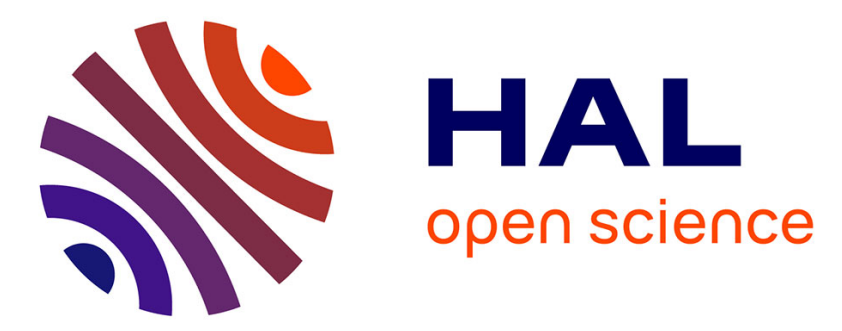

\title{
Composition-Switchable Liquid Crystalline Nanostructures as Green Formulations of Curcumin and Fish Oil
}

\author{
Miora Rakotoarisoa, Borislav Angelov, Shirly Espinoza, Krishna Khakurel, \\ Thomas Bizien, Markus Drechsler, Angelina Angelova
}

\section{To cite this version:}

Miora Rakotoarisoa, Borislav Angelov, Shirly Espinoza, Krishna Khakurel, Thomas Bizien, et al.. Composition-Switchable Liquid Crystalline Nanostructures as Green Formulations of Curcumin and Fish Oil. ACS Sustainable Chemistry \& Engineering, 2021, 9 (44), pp.14821-14835. 10.1021/acssuschemeng.1c04706 . hal-03445428

\section{HAL Id: hal-03445428 \\ https://hal.science/hal-03445428}

Submitted on 24 Nov 2021

HAL is a multi-disciplinary open access archive for the deposit and dissemination of scientific research documents, whether they are published or not. The documents may come from teaching and research institutions in France or abroad, or from public or private research centers.
L'archive ouverte pluridisciplinaire HAL, est destinée au dépôt et à la diffusion de documents scientifiques de niveau recherche, publiés ou non, émanant des établissements d'enseignement et de recherche français ou étrangers, des laboratoires publics ou privés. 


\title{
Composition-Switchable Liquid Crystalline Nanostructures as Green Formulations of Curcumin and Fish Oil
}

\author{
Miora Rakotoarisoa, ${ }^{\&}$ Borislav Angelov, ${ }^{\#}$ Shirly Espinoza, ${ }^{\#}$ Krishna Khakurel, ${ }^{\#}$ \\ Thomas Bizien, ${ }^{\S}$ Markus Drechsler ${ }^{\ddagger}$ and Angelina Angelova ${ }^{\&, *}$
}

${ }^{\&}$ Université Paris-Saclay, CNRS, Institut Galien Paris-Saclay UMR8612, F-92296 Châtenay-Malabry, France;

${ }^{\#}$ Institute of Physics, ELI Beamlines, Academy of Sciences of the Czech Republic, Na Slovance 2, CZ-18221 Prague, Czech Republic;

${ }^{\S}$ Synchrotron SOLEIL, l'Orme des Merisiers, Saint-Aubin - BP 48, 91192 Gif-surYvette Cedex, France;

${ }^{\ddagger}$ Keylab "Electron and Optical Microscopy", Bavarian Polymer Iinstitute (BPI), University of Bayreuth, Universitätsstrasse 30, D-95440 Bayreuth, Germany

\section{Corresponding Author}

*e-mail: angelina.angelova@universite-paris-saclay.fr (A.A.). 


\section{SYNOPSIS}

A phase diagram constructed from nanostuctural studies of sustainable liquidcrystalline delivery systems provides essential knowledge for development of dualloaded lipid nanoparticles

\section{ABSTRACT}

Green compositions and processes for fabrication of dual- and multi-loaded nanocarriers with antioxidant functionality and neuroprotective, cardioprotective, antiviral, and antiproliferative activities are of broad interest for innovations in pharmaceutics and nutraceutics. Co-encapsulation of curcumin (studied as a key multipurpose phytochemical antioxidant) with $\omega-3$ polyunsaturated fatty acids (PUFAs) (studied as active ingredients of natural fish oil) may increase the oxidative stability of selfassembled formulations aiming at development of "food drugs" and prevention of disease progression in various pathological states. The objective of this work is to prepare selfassembled lyotropic liquid crystalline nanostructures as dual-loaded biodegradable carriers of $\omega-3$ PUFA-fish oil and curcumin. A detailed structural phase diagram of ternary [monoolein (MO) - PEGylated lipid mixture] / [fish oil - curcumin] / water system is created. A composition-mediated switch between nanostructures of different topologies and polymorphic states is achieved through varying the ratios between the amphiphilic monoglyceride ingredient, fish oil and water, which yielded cubic, sponge, and lamellar mesophases of tunable nanoscale repeat spacings. Synchrotron small-angle X-ray scattering (SAXS) studies are performed with the lyotropic liquid crystalline nanostructures along compositional dilution lines. The temperature effect is examined at $22{ }^{\circ} \mathrm{C}$ and $5{ }^{\circ} \mathrm{C}$ with regard to preparation conditions and mesophase stability on storage. Bulk mesophases are dispersed into lipid nanoparticles at $22{ }^{\circ} \mathrm{C}$, the structures and topologies of which are revealed by SAXS and cryo-transmission electron microscopy (cryo-TEM) imaging. The new knowledge about the controlled multicomponent 
supramolecular assembly and the achieved stabilization of low-temperature cubic phases (hydrated in $5 \mathrm{wt} \% \mathrm{D}-(+)$-glucose) should facilitate the development of cost-effective stable and safe delivery systems of weakly soluble natural antioxidant compounds coencapsulated with $\omega-3$ PUFA oils.

KEYWORDS: Phytochemical antioxidant, nanocurcumin, lipid-based lyotropic liquid crystalline phases, sustainable nanoformulations, safe biodegradable cubosomes, fish oil, lipid nanoparticles, small-angle X-ray scattering

\section{INTRODUCTION}

Sustainable nanomedicine development relies on active ingredients and processing nanotechnologies that favor environmental protection. ${ }^{1-3}$ Fabrication processes based on spontaneous self-assembly avoid high energy consumption and therefore reduce the environmental pollution. Improving drug bioavailability is one of the major current objectives of the green pharma industry. As a matter of fact, increased bioavailability of the active ingredients will essentially diminish the need of drug elimination, and thus will prevent the risk for the environment. Due to their safety, high efficacy for drug nanoencapsulation, and low immunogenicity, lipid-based liquid crystalline carriers are gaining considerable interest in recent years. ${ }^{4-22}$ They are thermodynamically stable and permit development of sustained drug delivery systems in nanomedicine. ${ }^{23-33}$ 
Lipid-based nanoparticles fabricated from biocompatible and biodegradable natural sources provide safety profiles and the possibility for engineering of green nanosystems with controlled surface area-to-volume ratios. ${ }^{5,10-17,23}$ Such particles can be formed by dispersion of lipid-based lyotropic liquid crystalline (LLC) phases, which spontaneously self-assemble upon exposure of lyotropic lipids to water. ${ }^{11,17}$ The formation of lamellar $\left(\mathrm{L}_{\alpha} / \mathrm{L}_{\mathrm{c}}\right)$, bicontinuous cubic $\left(\mathrm{V}_{2}\right)$, inverted hexagonal $\left(\mathrm{H}_{\mathrm{II}}\right)$, sponge $\left(\mathrm{L}_{3}\right)$, fluid isotropic $\left(\mathrm{L}_{2}\right)$ or micellar cubic (I2) mesophases ${ }^{6,10,14-17,25-30}$ has been rationalized through the critical packing parameter $(\mathrm{CPP}) .{ }^{34}$ It defines the propensity of lipid compounds and amphiphilic lipid mixtures to form lamellar bilayer or curved membrane structures as a function of their molecular shapes. ${ }^{12,14-16,28,34}$ Amphiphilic molecules (for which the molecular space is dominated by a large hydrophobic volume relative to the crosssectional area of the hydrophilic head group) are characterized by a critical packing parameter (CPP) higher than 1 and tend to form inverse phases. ${ }^{10,30,34}$ Examples of nonlamellar phases include bicontinuous cubic, inverted hexagonal and sponge structures. ${ }^{10,15,28-30,35-40}$ Various additives and environment conditions may induce phase transitions between these supramolecular architectures. ${ }^{10,23-28,40-43}$

Dispersion of nonlamellar LLC assemblies in excess water (via high-energy fragmentation involving ultrasonication, microfluidization, and homogenization methods) yields liquid crystalline nanoparticles (LCNPs). ${ }^{6,11-14,16-25,27-31}$ Lipid nanoparticles derived from bicontinuous cubic phases, called cubosomes, have much higher surface area per volume than micellar and lamellar structures. ${ }^{6,14,16,23}$ This feature is advantageous for improving the bioavailability of encapsulated hydrophobic, hydrophilic or amphiphilic compounds. ${ }^{19}$ Cubosomes are being intensively studied for development of drug delivery 
carriers with anti-inflammatory, antimicrobial, antiviral, anticancer, neuroprotective and anti-dementia activities through different kinds of administration routes (oral, intranasal, transdermal, ophthalmic, or mucosal) as well as for protection of food ingredients. ${ }^{13,18-29}$ The monoglyceride lipid monoolein (MO or glycerol monooleate) (Fig. 1A) is one of the key lyotropic lipids suitable for the sustainable development of liquid crystalline delivery systems. $^{5,-13,20}$ It is a nonlamellar lipid which is nontoxic, biodegradable and biocompatible material, classified as GRAS (generally recognized as safe). ${ }^{13,30}$

The purpose of the present work is to design and prepare, by environmentally friendly green process, mixed amphiphilic assemblies favoring stable cubic phase formation in curcumin-loaded PEGylated MO-based lipid systems for inclusion of high $\omega-3$ polyunsaturated fatty acids (PUFA)-fish oil amounts. The rationale of the study considers that such safe lipid systems can solubilize molecules for various multi-targeted applications in combination therapy. The choice of co-encapsulation of curcumin and PUFA-fish oil in the same carrier is motivated by the purpose to achieve combined bimodal or multiple effects of the nanoformulations. First, curcumin (CU) is a natural plant-based multipurpose compound with antioxidant, antiviral, antibacterial, antifungal, anti-proliferative, anticancer, anti-inflammatory, neuroprotective and cardioprotective activities. ${ }^{44-60}$ This phytochemical agent receives growing attention as health-promoting nutraceutical and multipurpose pharmaceutical product because of its safe profile with low side effects. ${ }^{50-56}$ The major challenge is that $\mathrm{CU}$ has very low water solubility and low bioavailability. Moreover, $\mathrm{CU}$ can be chemically unstable depending on the environment $(\mathrm{pH}$, light, ...), which may cause a loss of biological activity and hampering its use as a free compound ${ }^{57}$ Studies have indicated that the CU bioavailability may be 
increased upon mixing with oils and amphiphilic lipids. ${ }^{60-63}$ For this reason, we choose to encapsulate CU in green lipid-based self-assembled systems.

Second, fish oil (FO) is chosen as a cost-effective natural source of $\omega$-3 PUFAs. It is attractive for nanomedicine and nutraceutical development owing to its numerous beneficial health effects. ${ }^{64} \mathrm{FO}$ is rich in eicosapentaenoic (EPA) and docosahexaenoic (DHA) acids, which are $\omega-3$ PUFAs with important preventive health applications against inflammation, infection, hypertension, asthma, cardiovascular disorders, cancer and neurodegenerative diseases. ${ }^{65-81}$ It should be noted that humans cannot synthesize PUFAs nor produce precursors of essential fatty acids (e.g. $\alpha$-linolenic acid). ${ }^{64}$ In the absence of previously published structural phase diagrams of PUFA-encapsulating lyotropic liquid crystalline self-assembled systems, FO, EPA, and DHA have been mostly formulated in nanoemulsions or in oil-in-water emulsions for oral supplementation. ${ }^{82-88}$ We consider that these lipophilic substances can be incorporated into synthetic liquid crystalline structures towards enhanced solubility and improved oxidative stability. ${ }^{89-97}$ It should be noted that $\omega-3$ PUFAs are mainly present in the form of triacylglycerides in FO (Fig. 1B). ${ }^{83}$ The possible use of $\omega-3$ PUFA monoglycerides as major lipid constituents in the development of liquid crystalline nanoparticles (LCNPs) for the delivery of nutraceuticals, therapeutic agents, or their combinations has recently been discussed. ${ }^{67-}$ $71,92,95$ 
(A)

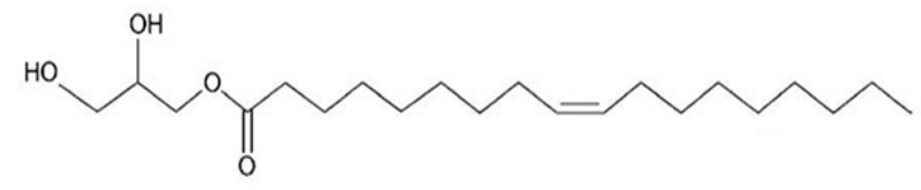

(B)

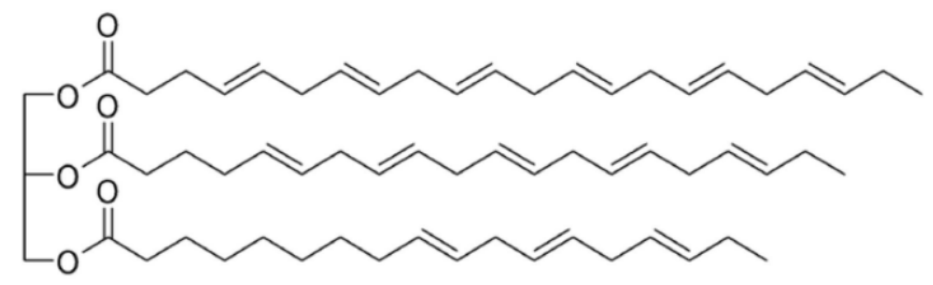

(C)

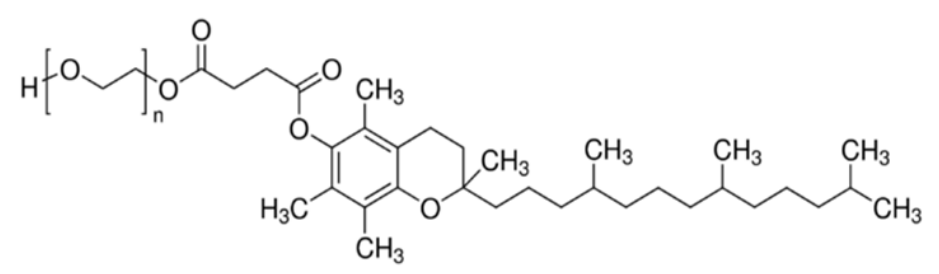

Figure 1. Chemical structures of the lipid components used for fabrication of green liquid crystalline nanocarriers: (A) Nonlamellar lipid monoolein (MO); (B) General formula of triacylglycerol indicating the presence of $\omega-3$ PUFA chains [e.g. docosahexaenoic acid (DHA; 22:6 n-3) and eicosapentaenoic acid (EPA; 20:5 n-3) chains] in fish oil (FO); and (C) PEGylated amphiphilic stabilizer D- $\alpha$-tocopheryl-poly(ethylene glycol)1000 (TPGS$\left.\mathrm{PEG}_{1000}\right)$.

In this work, we conceived and produced lipid-based nanocarriers with dual loading of curcumin and fish oil via a composition-tuning self-assembly methodology. ${ }^{15}$ The amphiphilic compositions with dual CU and FO loading were designated by the phase diagram shown in Figure 2. The preparations involve a constant fraction of $D-\alpha$ tocopheryl poly(ethylene glycol)1000 succinate (TPGS-PEG 1000 ) (Fig. 1C). The role of this vitamin E-derived PEGylated amphiphile is to facilitate the dispersion of stable lipid nanoparticles in diluted aqueous formulations (see the water-rich region marked in yellow color in Figure 2). Our choice of the MO/FO/CU/TPGS-PEG ${ }_{1000}$ mixed systems is further motivated by the fact that these amphiphilic compositions may serve for large 
scale cost-effective production of lipid nanoparticles and bulk phase LC formulations for supportive treatments and preventive health applications. The aqueous phase contained 5 wt\% $\mathrm{D}(+)$-glucose, a concentration that would be suitable for in vivo delivery applications or for cryopreservation of the studied formulations. The structural and morphological features of the generated liquid crystalline mesophases and lipid nanoparticles were investigated by means of synchrotron small-angle X-ray scattering (SAXS), cryogenic transmission electron microscopy (cryo-TEM) and quasi-elastic light scattering (QELS). The SAXS experiments were performed at room temperature and after that the temperature effect on the structural organization was examined under conditioning at temperature $5{ }^{\circ} \mathrm{C}$. Considering that both the natural plant-based compound curcumin and the marine-derived PUFAs are sensible to degradation in oxidizing media, it can be expected that the phytochemical antioxidant (CU) may exert protective action on the fish oil in the dual-loaded formulations in terms of oxidative stability. ${ }^{81,84}$ Owing to its hydrophobic nature, curcumin can be protected from expose to oxidizing environment upon its incorporation in the lipid bilayers of the created multicompartment nanocarriers. 


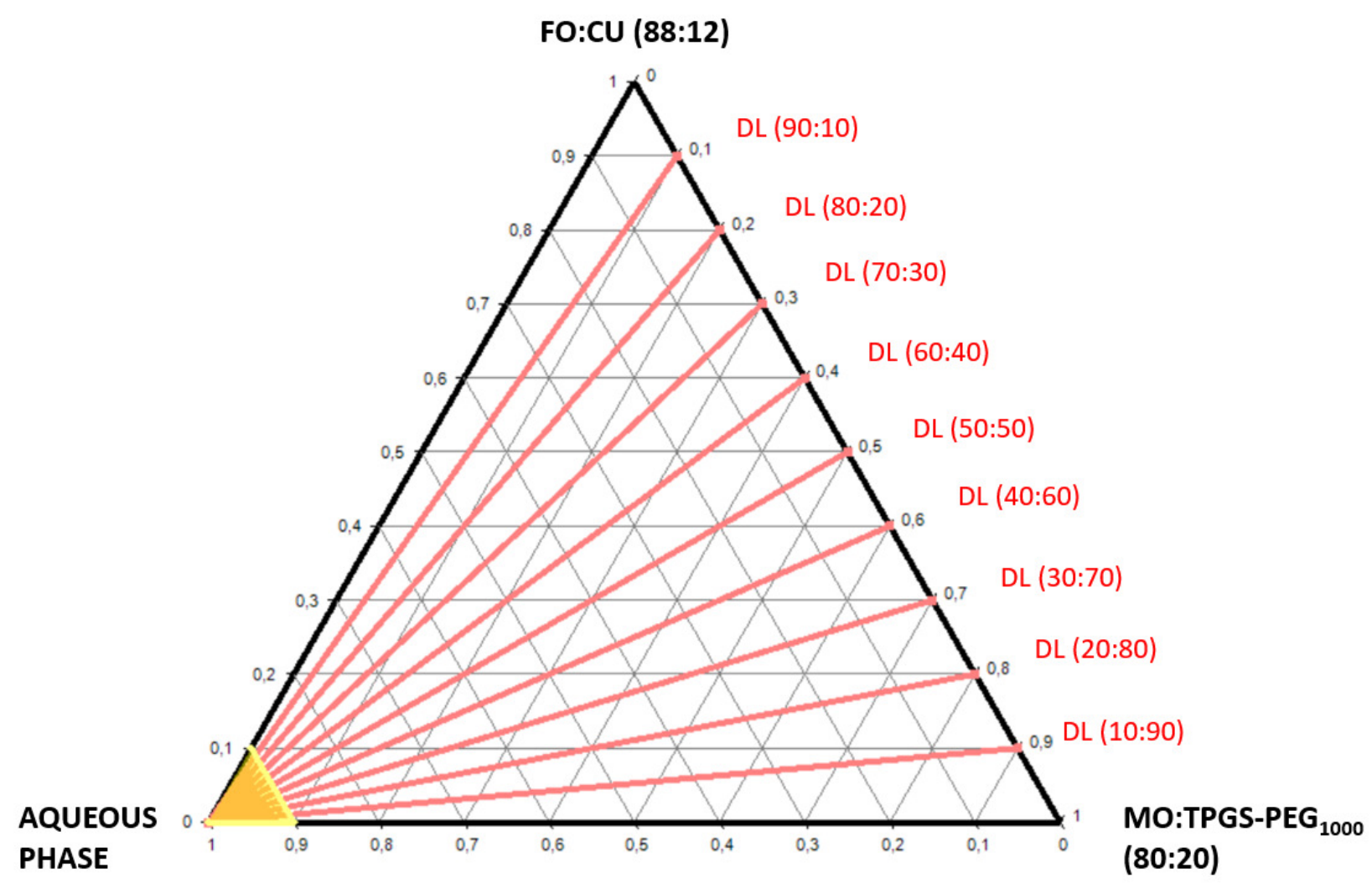

Figure 2. Phase diagram employed for designation of ten dilution lines for preparation of liquid crystalline nanocarriers composed of monoolein (MO), TPGS-PEG 1000 amphiphile, fish oil (FO), curcumin (CU), and aqueous phase containing D-(+)-glucose (5 wt\%). The lipid/co-lipid [MO:TPGS-PEG ${ }_{1000}$ ] and bioactive ingredients [FO:CU] weight ratios are kept constant at 80:20 and 88:12 (w/w\%) respectively. The water-rich region, serving for lipid nanoparticles dispersion, is represented by a yellow triangle. Experimental synchrotron small-angle X-ray scattering (SAXS) data were acquired for multiple compositions along the dilution lines drawn in red. For every composition studied, five measurements were averaged at two positions of the X-ray beam along the height of the samples sealed in capillaries.

\section{RESULTS AND DISCUSSION}




\section{Structural Organization of PEGylated Bulk Liquid Crystalline Systems}

Dependence of the Self-assembled Liquid Crystalline Structures on the Hydration Level of the PEGylated Lipid Mixtures

Monoolein and D- $\alpha$-tocopherol poly(ethylene glycol) 1000 succinate were mixed in thin lipid films and assembled in aqueous phase containing D-(+)-glucose (5 wt\% solution suitable for development of in vivo delivery formulations or for cryo-protection). The effect of the hydration level on the structural properties of the PEGylated blank lipid carriers was investigated at different lipid/water proportions. Synchrotron SAXS experiments were performed with MO/TPGS-PEG 1000 80:20 (w/w\%) lipid mixtures at water contents from 10 to $80 \mathrm{wt} \%$ at temperature $22^{\circ} \mathrm{C}$. In preliminary experiments, the 80:20 weight ratio MO/TPGS-PEG ${ }_{1000}$ was established to yield spontaneous formation of stable lipid nanoparticles upon dispersion of the self-assembled mixtures. Representative SAXS plots revealing the presence or absence of long-range periodicity in the structure of MO/TPGS-PEG ${ }_{1000} /$ water liquid crystalline assemblies are presented in Figure 3. Figure $3 \mathrm{~A}$ shows the structural results obtained at low water content $(<50 \mathrm{wt} \%)$ at $22^{\circ} \mathrm{C}$. At $10 \mathrm{wt} \%$, the SAXS pattern displays a single broad correlation peak centered at $q=$ $0.190 \AA^{-1}$ typical for lamellar precursors or onion phases..$^{24,52,55}$ The self-assembled system forms a lamellar phase with increasing water content from 20 to $40 \mathrm{wt} \%$. The determined repeat spacing of the lamellar phase at $20 \mathrm{wt} \%$ water content $(d=3.9 \mathrm{~nm})$ (Table 1) is slightly bigger than that of the lamellar precursor phase $(d=3.3 \mathrm{~nm})$ and progressively increases $(d=4.6 \mathrm{~nm})$ at $40 \mathrm{wt} \%$ water content. 
The structural results obtained at higher water contents $(\geq 50 \mathrm{wt} \%)$ and temperature of $22^{\circ} \mathrm{C}$ (Figure 3B) revealed two kinds of cubic structures with long-range threedimensional (3D) periodicities. They were identified by different sets of observed Bragg peaks, namely

(i) A bicontinuous gyroid cubic Ia3d phase was identified at 50-70 wt\% water content. Figure 3B shows the set of Bragg peaks with $q$-vector positions spaced in the ratio $\sqrt{6}: \sqrt{ } 8: \sqrt{14}: \sqrt{16}: \sqrt{ } 20: \sqrt{ } 22: \sqrt{ } 24: \sqrt{ } 26$. These Bragg peaks were assigned to the (211), (220), (321), (400), (420), (332), (422), and (431) reflections of a gyroid cubic lattice $\mathrm{Q}^{\mathrm{IIG}}$ (Ia3d space group);

(ii) A bicontinuous double diamond cubic Pn3m phase was identified at $80 \mathrm{wt} \%$ water content. Figure 3B shows the set of Bragg peaks with $q$-vector positions spaced in the ratio $\sqrt{2}: \sqrt{ } 3: \sqrt{ } 4: \sqrt{6}: \sqrt{ } 8: \sqrt{ } 9: \sqrt{10}: \sqrt{ } 11: \sqrt{ } 12: \sqrt{ } 14$. The observed Bragg peaks were assigned to the (110), (111), (200), (211), (220), (221), (310), (311), and (222) reflections of a double diamond cubic lattice $\mathrm{Q}^{\mathrm{IID}}$ (Pn3m space group). The (321) reflections was weak at ambient temperature.

The determined internal structures and repeat spacings of the studied MO/TPGS$\mathrm{PEG}_{1000}$ self-assembled architectures are summarized in Table 1. The unit cell lattice parameters of the cubic structures, $\mathrm{a}_{(\mathrm{Q})}$, were calculated from the reciprocal slope of the linear plots $q\left(\AA^{-1}\right)$ versus $\left(h^{2}+k^{2}+l^{2}\right)^{1 / 2}$, where $(h k l)$ are the Miller indices of the detected Bragg peaks (Eq. 1),

$$
q=\left(2 \pi / \mathrm{a}_{(\mathrm{Q})}\right)\left(h^{2}+k^{2}+l^{2}\right)^{1 / 2}
$$


A

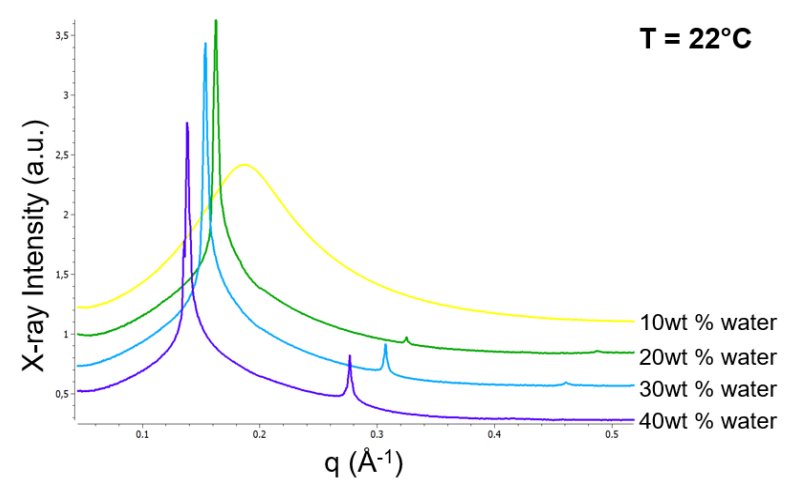

B

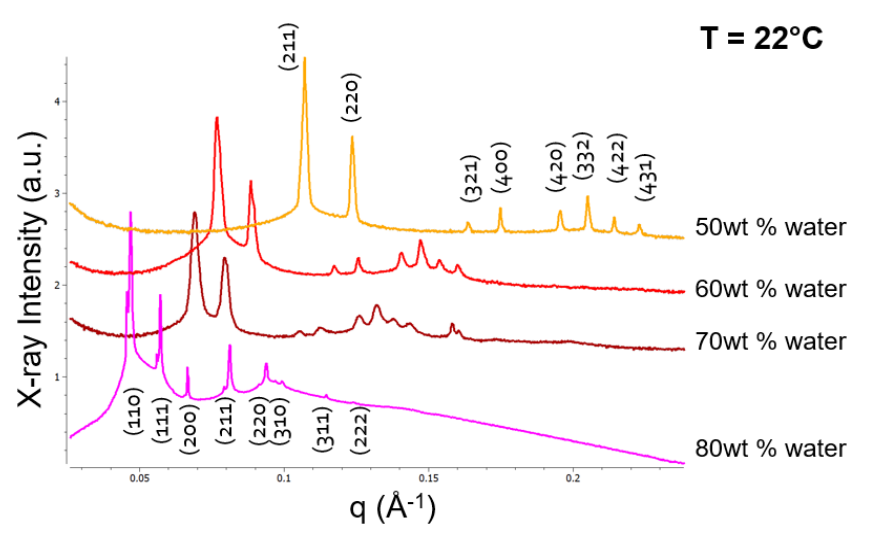

C

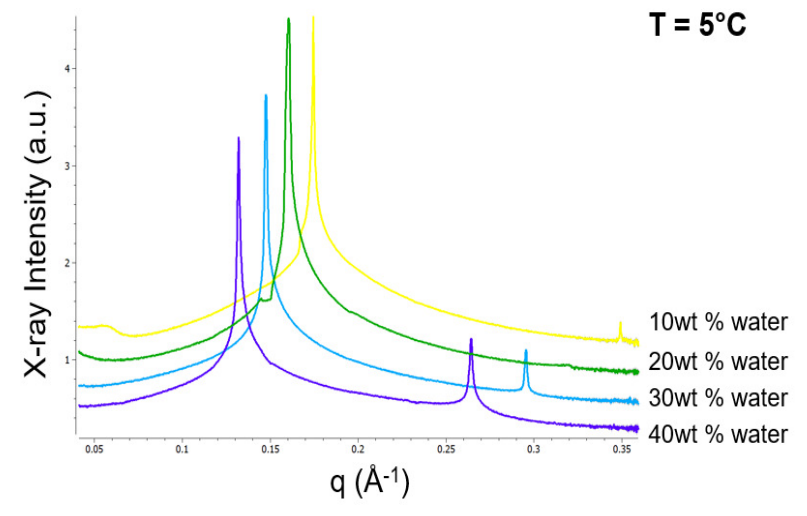

D

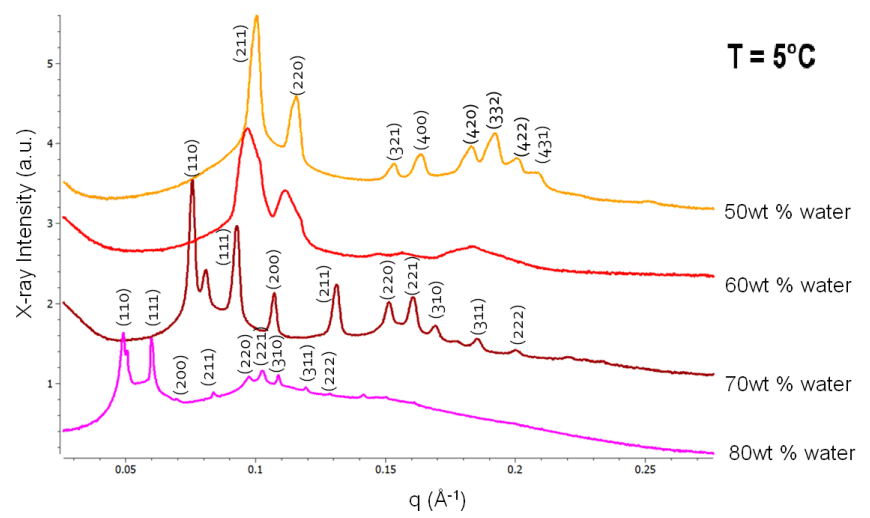

Figure 3. Representative synchrotron SAXS patterns of self-assembled MO/TPGS$\mathrm{PEG}_{1000} /$ water mixtures showing the dependence of the mesophase-structure type on the varying hydration level [D-(+) glucose $(5 \mathrm{wt} \%)$ solution] at two temperatures: $22^{\circ} \mathrm{C}$ (ambient condition) and $5^{\circ} \mathrm{C}$ (storage condition in a refrigerator). (A) SAXS pattern revealing the formation of a lamellar precursor phase at $10 \mathrm{wt} \%$ water content and a lamellar phase $\left(\mathrm{L}_{\alpha}\right)$ at water contents from $20 \mathrm{wt} \%$ to $40 \mathrm{wt} \%$ at $22^{\circ} \mathrm{C}$. (B) SAXS patterns displaying Bragg peaks that are indicative of formation of periodic liquid crystalline phases, namely a gyroid Ia3d cubic structure at 50-70 wt\% water content and a bicontinuous double diamond $\mathrm{Pn} 3 \mathrm{~m}$ cubic structures at $80 \mathrm{wt} \%$ water content at $22^{\circ} \mathrm{C}$. The Bragg peak splitting, observed with the sample of 80 wt $\%$ water content, results from uneven lipid hydration likely due to inhomogeneous mixing. (C) SAXS patterns corresponding to lamellar phase formation at 10-40 wt $\%$ water content at $5^{\circ} \mathrm{C}$. (D) SAXS patterns of bicontinuous cubic liquid crystalline phases of the gyroid Ia3d and the double 
diamond $\mathrm{Pn} 3 \mathrm{~m}$ cubic crystallographic space groups observed at $5^{\circ} \mathrm{C}$ for $50-60 \mathrm{wt} \%$ and above 70 wt $\%$ water contents, respectively. The Bragg peak splitting, observed with the sample of 80 wt \% water content, results from uneven lipid hydration likely due to inhomogeneous mixing. The aqueous phase contains D-(+)-glucose (5 wt \%).

Table 1. Internal liquid crystalline structure types, repeat spacings $(d)$ or cubic unit cell lattice parameters, $\mathrm{a}_{(\mathrm{Q})}$, of hydrated MO/TPGS-PEG ${ }_{1000}[80: 20(\mathrm{w} / \mathrm{w} \%)]$ self-assembled architectures determined by SAXS analyses of the structural data presented in Figure 3.

\begin{tabular}{|c|c|c|c|c|}
\hline \multirow[b]{2}{*}{$\begin{array}{l}\text { Water } \\
\text { content } \\
(w t \%)\end{array}$} & \multicolumn{2}{|c|}{$\mathrm{T}=22^{\circ} \mathrm{C}$} & \multicolumn{2}{|c|}{$\mathbf{T}=5^{\circ} \mathrm{C}$} \\
\hline & LLC structures & $\begin{array}{c}\text { Repeat spacing } \\
(d) \\
\text { or Lattice } \mathbf{a}_{(Q)} \\
(\mathbf{n m})\end{array}$ & LLC structures & $\begin{array}{c}\text { Repeat } \\
\text { spacing }(d) \\
\text { or Lattice } \mathbf{a}_{(Q)} \\
(n m)\end{array}$ \\
\hline 10 & $\begin{array}{l}\text { Lamellar } \\
\text { precursor }\end{array}$ & 3.3 & Lamellar & 3.5 \\
\hline 20 & Lamellar & 3.9 & Lamellar & 3.9 \\
\hline 30 & Lamellar & 4.1 & Lamellar & 4.2 \\
\hline 40 & Lamellar & 4.6 & Lamellar & 4.8 \\
\hline 50 & Ia3d cubic & 14.3 & Ia3d cubic & 15.2 \\
\hline 60 & Ia3d cubic & 19.9 & $\begin{array}{c}\text { Cubic } \\
\text { intermediate }\end{array}$ & $(15.2-16.1)$ \\
\hline 70 & Ia3d cubic & 22.2 & $\begin{array}{c}\text { Cubic } \\
\text { intermediate / } \\
\text { Pn3m cubic } \\
\text { coexistence }\end{array}$ & (17.9) / 11.7 \\
\hline 80 & $\begin{array}{c}P n 3 m / P n 3 m \\
\text { cubic } \\
\text { coexistence }\end{array}$ & $\begin{array}{l}19.3 / \\
18.9\end{array}$ & $\begin{array}{c}P n 3 m / P n 3 m \\
\text { cubic } \\
\text { coexistence }\end{array}$ & $\begin{array}{l}18.4 / \\
18.2\end{array}$ \\
\hline
\end{tabular}

The estimated cubic Ia3d and Pn3m unit cell lattice parameters are in the range of $\mathrm{a}_{\mathrm{Q} 1(\mathrm{Ia} 3 \mathrm{~d})}=14.3-22.2 \mathrm{~nm}$ and $\mathrm{a}_{\mathrm{Q} 2(\mathrm{Pn} 3 \mathrm{~m})}=18.9-19.3 \mathrm{~nm}$, respectively. Table 1 indicates that the cubic Ia3d unit cell lattice parameter increases with the increase of the water content. The excess water point for the MO/TPGS-PEG 1000 system was established to be 
beyond $80 \mathrm{wt} \%$ water content. At variance, the excess water point for the pure $\mathrm{MO} / \mathrm{water}$ system has been determined to be around $60 \mathrm{wt} \%$ water content. ${ }^{30,36,37}$

It can be concluded from these SAXS results that that the PEGylation of the selfassembled monoglyceride lipid system (MO/TPGS-PEG ${ }_{1000}$ ) requires more hydration water (with regard to pure MO) in order for a structural transformation of the lamellar mesophase to a fully hydrated bicontinuous cubic mesophase to occur (Figs. 3A,3B). The determined cubic unit cell lattice parameter of the PEGylated lipid double-diamond type cubic phase MO/TPGS-PEG ${ }_{1000}\left(\mathrm{a}_{\mathrm{Q}(\mathrm{Pn} 3 \mathrm{~m})}=19.3-18.9 \mathrm{~nm}\right)$ is bigger that that of the corresponding pure $\mathrm{MO} /$ water cubic phase $\left(\mathrm{a}_{\mathrm{Q}(\mathrm{Pn} 3 \mathrm{~m})}=10.5 \mathrm{~nm}\right) .{ }^{5,15}$

Effect of Low Temperature on the PEGylated Mixed Amphiphilic MO/TPGS-PEG ${ }_{1000}$ Liquid Crystalline Assemblies

To investigate the effect of low storage temperature on the hydrated MO/TPGSPEG $_{1000}$ self-assembled mixtures, synchrotron SAXS experiments were also performed at $5^{\circ} \mathrm{C}$ for the same water concentrations from 10 to $80 \mathrm{wt} \%$. Representative SAXS plots revealing the long-range periodicities of the hydrated MO/TPGS-PEG ${ }_{1000}$ assemblies at $5^{\circ} \mathrm{C}$ are shown in Figures 3C and 3D. Lowering the temperature down to $5^{\circ} \mathrm{C}$ caused the formation of lamellar structures within the range from $10 \mathrm{wt} \%$ to $40 \mathrm{wt} \%$ water contents. The cubic structures were preserved above $50 \mathrm{wt} \%$ water content. A cubic $(I a 3 d-P n 3 m)$ phase transition was observed above $60 \mathrm{wt} \%$ hydration level. The bicontinuous double diamond cubic Pn $3 m$ phase emerged at $70 \mathrm{wt} \%$ hydration, whereas it was stabilized at 80 wt $\%$ water content at $22^{\circ} \mathrm{C}$ (Figure 3D). 
The SAXS pattern of the sample with $70 \mathrm{wt} \%$ water content was ascribed to a cubic intermediate/Pn3m cubic phase coexistence at $5^{\circ} \mathrm{C}$ (Figure 3D). The additional unassigned Bragg peak between the (110) and (111) reflections of the Pn3m cubic phase was attributed to a domain of a cubic phase structural intermediate. The estimated structural parameters corresponding to the cubic intermediate/Pn $3 m$ cubic coexistence are given in Table 1. The bicontinuous double diamond Pn3m cubic structure, which formed at $80 \mathrm{wt} \%$ water content at $5^{\circ} \mathrm{C}$, displays broader Bragg peaks as compared to those recorded at temperature $22^{\circ} \mathrm{C}$. This reveals decreased ordering in the mesophase organization. In our opinion, the low-temperature cubic phase should be regarded as a metastable one taking into account that its destabilization and phase transformation upon cooling appear to be retarded by the incorporation of PEGylated chains at the lipid membrane interfaces as well as by the presence of $5 \mathrm{wt} \% \mathrm{D}-(+)$-glucose in the aqueous environment.

Indeed, the performed structural investigation with the MO/TPGS-PEG ${ }_{1000} /$ water system indicated the occurrence of lamellar-cubic and cubic-cubic phase transitions at higher water contents than those for the pure $\mathrm{MO} /$ water system. The phase diagram of the latter has been previously studied by Lutton and Caffrey et al. ${ }^{36-38}$ The authors have constructed lipid/water phase diagrams spanning the composition region from 0 to 50 wt $\%$ aqueous phase content. At low water content $(<10 \mathrm{wt} \%)$, the lamellar $\left(\mathrm{L}_{\mathrm{c}}\right)$ phase melts upon increasing temperature into an isotropic phase. ${ }^{36} \mathrm{~A}$ phase transition to a lamellar liquid crystalline phase $\left(\mathrm{L}_{\alpha}\right)$ takes place from 10 to $20 \mathrm{wt} \%$ hydration for the pure $\mathrm{MO} /$ water system. It melts into a $\mathrm{L}_{2}$ phase at increasing temperature. Whereas the transition to a bicontinuous cubic $I a 3 d$ phase begins at about $25 \mathrm{wt} \%$ hydration in the 
$\mathrm{MO} /$ water system, it takes place at $50 \mathrm{wt} \%$ hydration level in the MO/TPGS$\mathrm{PEG}_{1000} /$ water system studied here. This significant structural difference between the $\mathrm{MO} /$ water and the MO/TPGS-PEG 1000 /water assemblies is evidently due to the PEGylation of the lipid mixture by the TPGS-PEG 1000 agent as the PEGylation is known to influence the mesophase stability. ${ }^{40,41}$ In our study, the bicontinuous cubic structures were maintained in the region of $50-80 \mathrm{wt} \%$ water content. The resulting PEGylated cubic structures are of interest for the preparation of stable lipid mesophase nanoparticles by a green self-assembly process upon dilution.

\section{Structural Characterization of Dual-Loaded Bulk Liquid Crystalline Systems}

\section{Modulation of the Bulk Liquid Crystalline Structures by the Hydration Level at Constant} Curcumin and Fish Oil Loading in the Lipid Assemblies

To investigate the effect of the hydration level on the structural properties of CU- and FO-loaded liquid crystalline phases, generated using the MO/TPGS-PEG 1000 mixtures, synchrotron SAXS experiments were performed along the dilution lines drawn in Figure 2 (from 10 to $80 \mathrm{wt} \%$ ) at $22^{\circ} \mathrm{C}$. In these measurements, the $\mathrm{FO}$ quantity is constant with regard to MO, while the water quantity varies. The most significant changes are shown with representative SAXS patterns in Figure 4. The associated structural transitions are summarized in Figure 6 below.

SAXS plots revealing the presence or absence of long-range periodicities in the MO/TPGS-PEG $1000 / \mathrm{FO} / \mathrm{CU} /$ water assemblies are shown for two fixed lipid weight ratios 20:80 and 60:40 (w/w\%) between fish oil and monoolein in the amphiphilic mixtures [FO:CU]/[MO:TPGS-PEG 1000$]$ (Figure 4). The hydration of the two types of MO/TPGS$\mathrm{PEG}_{1000} / \mathrm{FO} / \mathrm{CU}$ mixtures was found to induce the formation of a sponge $\left(\mathrm{L}_{3}\right)$ phase at water contents below $\leq 30 \mathrm{wt} \%$ (see Figures $4 \mathrm{~A}$ and $4 \mathrm{C}$ for the weight ratios 20:80 and 
$60: 40 \mathrm{w} / \mathrm{w} \%)$. The observed shape of the scattering curves is similar to that typical for a sponge lipid phase. ${ }^{15,40}$ The sponge phase is a bicontinuous phase, which involves a 3D lipid bilayer membrane surrounded by two water channel networks. At variance to the bicontinuous lipid cubic phases, ${ }^{15,30,39,42}$ the sponge phase is not periodically ordered and it is of more fluid nature. Here, the SAXS patterns acquired at low water contents $(\leq 30$ $\mathrm{wt} \%$ ) were attributed to a sponge phase formation (Figures $4 \mathrm{~A}$ and $4 \mathrm{C}$ ). 
A

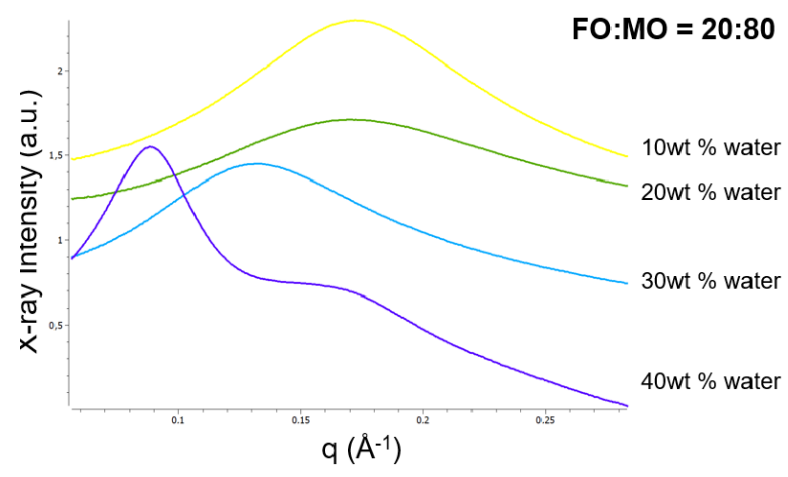

B

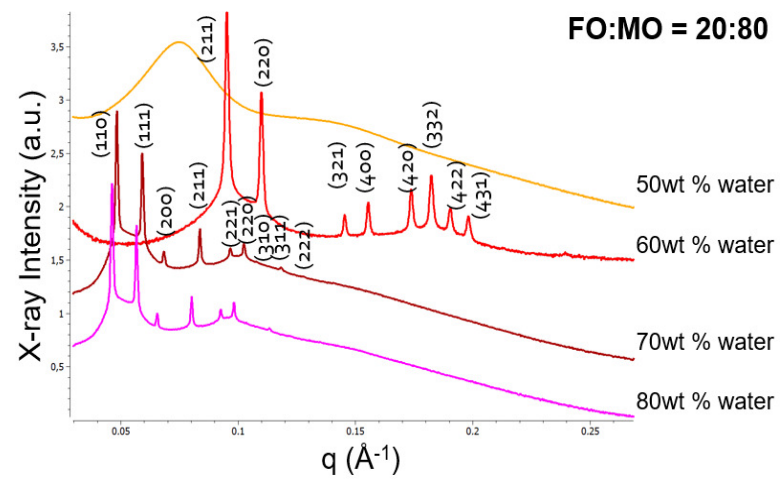

C

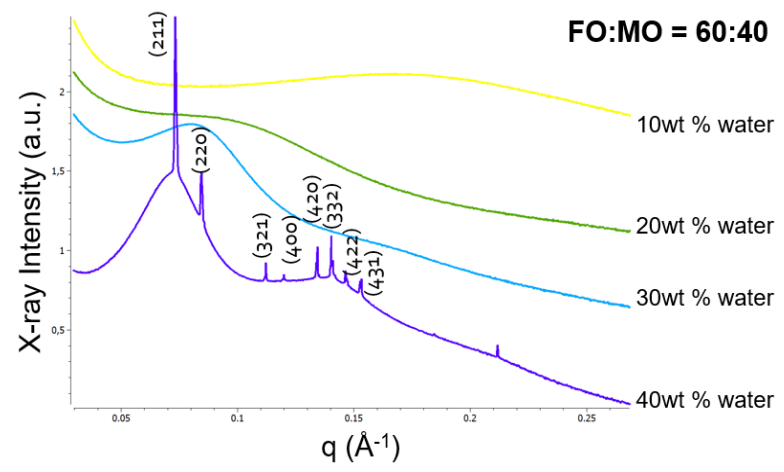

D

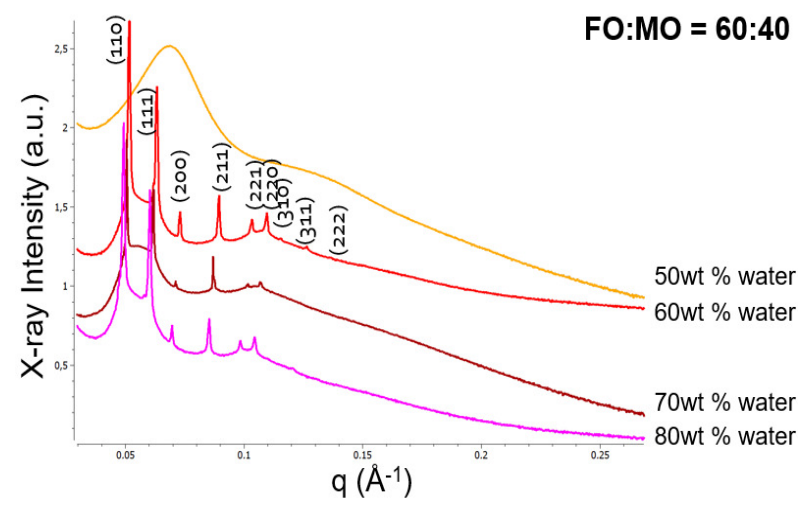

Figure 4. Representative SAXS patterns of self-assembled MO/TPGS$\mathrm{PEG}_{1000} / \mathrm{FO} / \mathrm{CU} /$ water mixtures with weight ratios between fish oil and monoolein 
[FO:CU]/[MO:TPGS-PEG $\left.{ }_{1000}\right]$ equal to $20: 80$ and 60:40 (w/w\%) and hydration performed at $22{ }^{\circ} \mathrm{C}$. (A-C) SAXS patterns corresponding to sponge phases and intermediate mesophase states at 10-40 wt\% water contents. (B-D) The recorded Bragg peaks are indicative of the formation of bicontinuous cubic gyroid Ia3d or double diamond Pn3m cubic structures at 60-80 wt $\%$ water contents. The aqueous phase contains D-(+)-glucose (5 wt \%).

Increase of hydration above $30 \mathrm{wt} \%$ led to structural transitions to precursors of cubic mesophases at $40 \mathrm{wt} \%$ and $50 \mathrm{wt} \%$ water contents (Figures 4A-4D). The SAXS patterns showed intermediate types of mesophase states and a coexistence of sponge and cubic structures at 40 to $50 \mathrm{wt} \%$ water contents. At high water concentrations $\geq 60 \mathrm{wt} \%$, the SAXS patterns were mostly attributed to the formation of bicontinuous diamond cubic phases at both lipid weight ratios 20:80 and 60:40 (w/w). A gyroid Ia3d bicontinuous cubic phase was identified in the SAXS plots recorded at $60 \mathrm{wt} \%$ water content. This is a relatively weakly hydrated state of a bicontinuous lipid cubic phase involving lower water amount. The higher water contents $>60 \mathrm{wt} \%$ yielded the formation of a swollen double diamond type Pn3m cubic phase $\left(\mathrm{D}_{\text {Large }}\right)$ with a lattice parameter $\mathrm{a}_{\mathrm{Q}(\mathrm{Pn} 3 \mathrm{~m})}=19.1$ $\mathrm{nm}$. The results for the determined unit lattice parameters of the bulk cubic liquid crystalline structures are summarized in Table 2. The estimated cubic $1 a 3 d$ and Pn $3 m$ unit cell lattice parameters are $\mathrm{a}_{\mathrm{Q}_{(\mathrm{Ia} 3 \mathrm{~d})}}=16.1 \mathrm{~nm}$ and $\mathrm{a}_{\mathrm{Q} 2(\mathrm{Pn} 3 \mathrm{~m})}=17.5-19.1 \mathrm{~nm}$, respectively. The obtained data indicated that the cubic Pn3m unit lattice parameter increases with the increase of the water content, which corresponds to swelling of the 3D nanochannel 
networks and the induction of swollen double diamond type Pn3m cubic phases $\left(\mathrm{D}_{\text {Large }}\right)^{39,40,96}$

Therefore, it can be deduced that the water content has a strong impact on the structural properties of the studied MO/TPGS-PEG ${ }_{1000} / \mathrm{FO} / \mathrm{CU}$ assemblies. Structural transitions were established in the order: Sponge phase - Cubic phase precursors Weakly hydrated gyroid Ia3d cubic phase - Swollen double diamond Pn3m cubic phase ( $\mathrm{D}_{\text {Large }}$ ) (Figure 4$)$. The sponge phase and the weakly ordered cubic structures, coexisting with sponge-type membranes, were obtained at 10 - $50 \mathrm{wt} \%$ water contents (Figure 4). The bicontinuous cubic structures were maintained at $60-80 \mathrm{wt} \%$ water contents upon the incorporation of both bioactive ingredients fish oil and curcumin. The results in Table 2 reveal that the encapsulated FO acts towards the swelling of the bicontinuous $P n 3 m$ cubic phase.

Table 2. Internal liquid crystalline structure types and cubic lattice parameters, $\mathrm{a}_{(\mathrm{Q})}$, of hydrated $\mathrm{MO} / \mathrm{TPGS}-\mathrm{PEG}_{1000} / \mathrm{FO} / \mathrm{CU} /$ water $\quad(5 \mathrm{wt} \% \mathrm{D}-(+)$-glucose $)$ self-assembled systems determined by SAXS analyses of the structural data shown in Figures 4B and 4D. Temperature is $22^{\circ} \mathrm{C}$.

\begin{tabular}{|c|c|c|c|c|}
\hline \multirow{2}{*}{$\begin{array}{c}\text { Water } \\
\text { content } \\
(\mathbf{w t} \%)\end{array}$} & \multicolumn{2}{|c|}{$\begin{array}{c}\text { [FO:CU]/[MO:TPGS-PEG } \\
\text { ratio } 20: 80\end{array}$} & $\begin{array}{r}\text { [FO:CU]/[MO:TPGS-PEG } \\
(\mathbf{w} / \mathbf{w} \%)\end{array}$ & $\begin{array}{c}\text { ratio } \\
\mathbf{6 0}: \mathbf{4 0}(\mathbf{w} / \mathbf{w} \%)\end{array}$ \\
\cline { 2 - 5 } & LLC structures & $\begin{array}{c}\text { Lattice } \\
\mathbf{a}_{(\mathbf{Q})}(\mathbf{n m})\end{array}$ & LLC structures & $\begin{array}{c}\text { Lattice } \\
\mathbf{a}_{(\mathbf{Q})}(\mathbf{n m})\end{array}$ \\
\hline 50 & $\begin{array}{c}\text { Sponge }- \text { cubic } \\
\text { intermediate }\end{array}$ & - & $\begin{array}{c}\text { Sponge }- \text { cubic } \\
\text { intermediate }\end{array}$ & - \\
\hline 60 & $I a 3 d$ cubic & 16.1 & $P n 3 m$ cubic & 17.5 \\
\hline 70 & $P n 3 m$ cubic & 18.5 & $P n 3 m$ cubic & 17.5 \\
\hline 80 & $P n 3 m$ cubic & 19.1 & $P n 3 m$ cubic & 18.6 \\
\hline
\end{tabular}


Impact of the Fish Oil/Monoolein Weight Ratio on the Bulk Liquid Crystalline SelfAssembled Structures

To gain more insight into the impact of the fish oil content on the inner structural organization of the bulk MO/TPG-PEG ${ }_{1000} / \mathrm{FO} / \mathrm{CU} /$ water assemblies, a series of synchrotron SAXS experiments was performed with eight lipid weight ratios 10/90, 20/80, 30/70, 40/60, 50/50, 60/40, 70/30 and 80/20 (w/w\%) between fish oil and monoolein at $22^{\circ} \mathrm{C}$ (Figure 5). The [FO:CU]/[MO:TPGS-PEG $\left.{ }_{1000}\right]$ self-assembled lipid mixtures were hydrated by a solution of D- $(+)$ glucose $(5 \mathrm{wt} \%)$. Different fixed water contents were examined: (i) $30 \mathrm{wt} \%$ aqueous phase representing the low water content region; (ii) intermediate $60 \mathrm{wt} \%$ water content region; (iii) $80 \mathrm{wt} \%$ high-water content region, and (iv) $95 \mathrm{wt} \%$ aqueous phase corresponding to the large excess water region.

The SAXS plots in Figure 5A were attributed to sponge phase formation upon incorporation of FO in the host MO lipid phase at $30 \mathrm{wt} \%$ water content. Previous studies of oil/MO systems yielded similar shapes of the SAXS patterns. ${ }^{4,94}$ The SAXS curves in Figure 5A indicated that the correlation length of the sponge-phase membranes, formed at $30 \mathrm{wt} \%$ water content and $22^{\circ} \mathrm{C}$, depends on the fish oil/monoolein (FO:MO) weight ratio. Interestingly, the SAXS pattern recorded at a lipid ratio 80:20 (w/w) shows peaks, which are characteristic of a coexistence of bicontinuous sponge and cubic Ia3d phases. ${ }^{15,40}$ This coexistence is observed also at $60 \mathrm{wt} \%$ water content at temperature of $22^{\circ} \mathrm{C}$ (Fig. 5B). The coexistence of sponge and cubic phases, or the formation of a single cubic phase, were strongly dependent on the fish oil/monoolein ratio. The obtained data were used for the construction of the phase diagram of the MO/TPGS$\mathrm{PEG}_{1000} / \mathrm{FO} / \mathrm{CU} /$ water system (see Figure 6 below).

Figure $5 \mathrm{C}$ presents the SAXS patterns of the samples prepared at $80 \mathrm{wt} \%$ water content at $22^{\circ} \mathrm{C}$, which show Bragg peaks characteristic of the double diamond cubic Pn $3 m$ space 
group at all FO:MO weight ratios. The cubic unit cell lattice parameters of the examined eight systems ranged from 15.9 to $19.1 \mathrm{~nm}$ (Table 3). A transition state between the cubic $P n 3 m$ and $\operatorname{Im} 3 m$ structures occurred at $95 \mathrm{wt} \%$ water content. At $22^{\circ} \mathrm{C}$, the phase transition led to the appearance of Bragg peaks with $q$-vector positions spaced in the ratio $\sqrt{2}: \sqrt{ } 4: \sqrt{6}: \sqrt{ } 8: \sqrt{ } 10: \sqrt{ } 12: \sqrt{ } 14: \sqrt{ } 16: \sqrt{ } 18$. These peaks were assigned to (110), (200), (211), (220), (310), (222), (321), (400) and (330) reflections of a primitive cubic lattice $\left(\mathrm{Q}^{\mathrm{IIP}}\right)$ of the $\mathrm{Im} 3 m$ crystallographic space group. Peaks indicating a coexistence of Pn3m and $\operatorname{Im} 3 m$ cubic phase domains were observed with FO:MO ratios 10:90 and 20:80 (w/w) as well. The phase coexistences are indicated in Table 3.

A

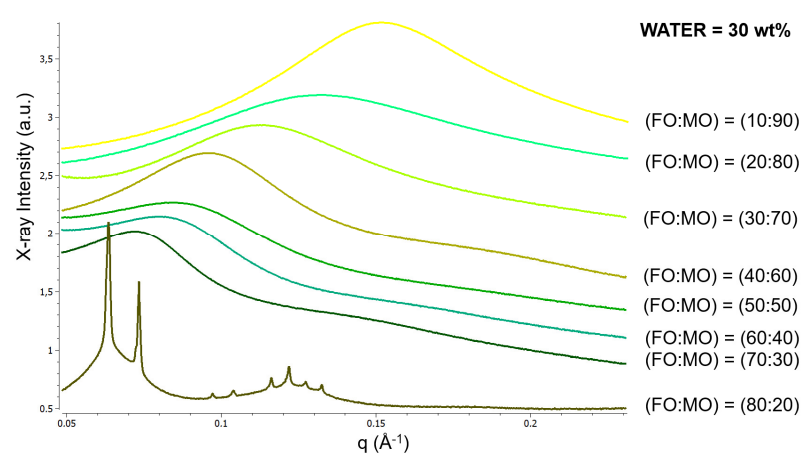

B

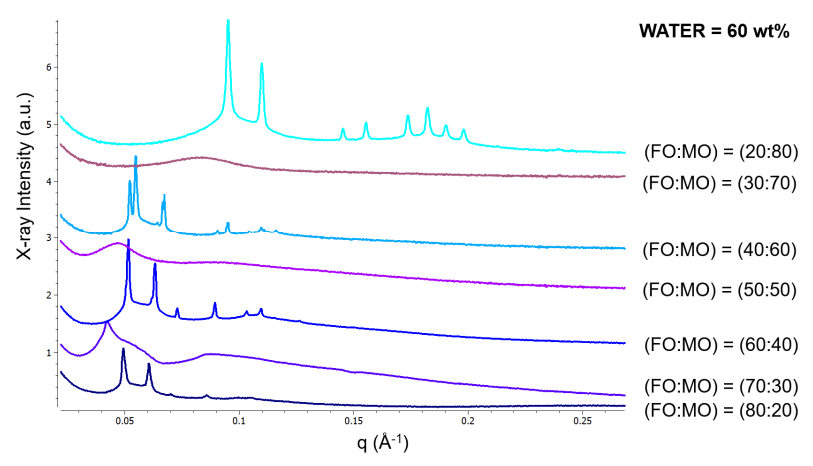

C

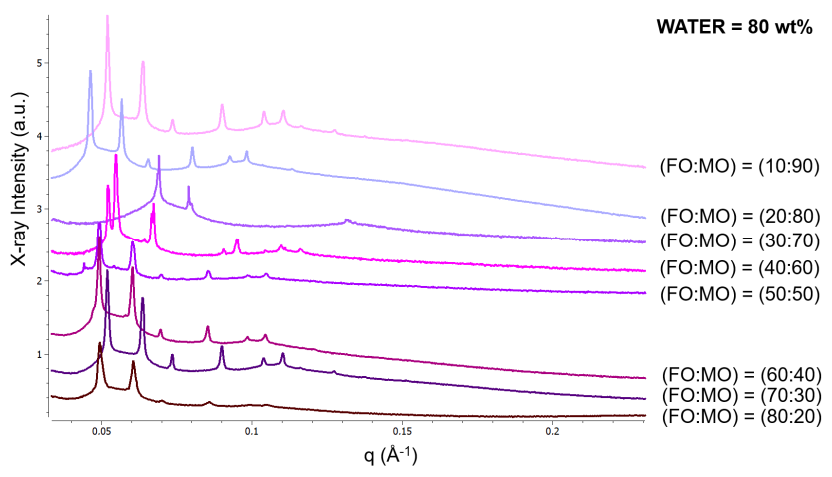

D

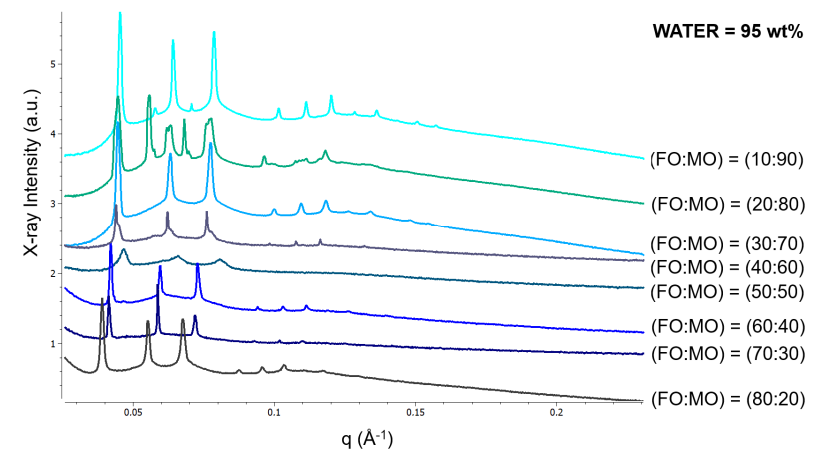

Figure 5. Representative SAXS patterns of $\mathrm{MO} / \mathrm{TPGS}-\mathrm{PEG}_{1000} / \mathrm{FO} / \mathrm{CU} /$ water selfassembled systems hydrated with a D-(+) glucose (5 wt $\%)$ solution at eight different 
weight ratios [FO:CU]/[MO:TPGS-PEG $\left.{ }_{1000}\right]$ between fish oil and monoolein at $22{ }^{\circ} \mathrm{C}$. (A) Sponge phase at $30 \mathrm{wt} \%$ water content for all [FO:MO] ratios except (80:20); (B) Sponge and cubic phases at 60 wt\% water content; (C) Bicontinuous cubic Pn3m phase at 80 wt \% water content, and (D) Primitive cubic $\operatorname{Im} 3 m$ phase at 95 wt\% water content. The aqueous phase contains D-(+)-glucose (5 wt $\%)$.

The intermediate phase state between the cubic Pn3m and $\operatorname{Im} 3 m$ structures, and the increase of the lattice parameter determined at 80 to $95 \mathrm{wt} \%$ water contents, appear to be affected by the increased fraction of fish oil and curcumin under excess water conditions. Transformations dependent on the oil composition and water contents were also revealed by the shifts in the unit cell lattice parameter of the cubic Im $3 m$ phase in the range from 18.9 to $23.1 \mathrm{~nm}$ (Table 3). As the fish oil content increases, the Bragg peaks shift towards lower $q$-vector values (Fig. 5D), which evidences the increase of the cubic unit cell lattice parameters (respectively swelling of the cubic structures). The lattice parameter is generally bigger for mixed lipid systems involving longer chain fatty acids. ${ }^{98}$

Table 3. Internal cubic liquid crystalline structure types and cubic unit cell lattice parameters, $\mathrm{a}_{(\mathrm{Q})}$, of MO/TPGS-PEG ${ }_{1000} / \mathrm{FO} / \mathrm{CU} /$ water systems, self-assembled in excess water (5 wt\% D-(+)-glucose), which were determined from SAXS analysis of the data shown in Figures 5C and 5D. Temperature is $22^{\circ} \mathrm{C}$.

\begin{tabular}{|l|c|r|r|r|}
\hline \multirow{2}{*}{$\begin{array}{l}\text { [FO:CU]/[MO:TPGS- } \\
\left.\text { PEG }_{1000}\right] \text { ratio (w/w \%) }\end{array}$} & WLC & Lattice & LLC structures & Lattice \\
\cline { 2 - 4 } & structures & $\mathbf{a}_{(Q)}(\mathrm{nm})$ & & $\mathbf{a}_{(\mathrm{Q})}(\mathrm{nm})$ \\
\hline
\end{tabular}




\begin{tabular}{|c|c|c|c|c|}
\hline 10:90 & $P n 3 m$ cubic & 17.1 & $\begin{array}{c}P n 3 m / \operatorname{Im} 3 m \\
\text { cubic } \\
\text { coexistence }\end{array}$ & $\begin{aligned} P n 3 m & =16.4, \\
\operatorname{Im} 3 m & =19.8\end{aligned}$ \\
\hline $20: 80$ & Pn3m cubic & 19.1 & $\begin{array}{c}P n 3 m / \operatorname{Im} 3 m \\
\text { cubic } \\
\text { coexistence }\end{array}$ & $\begin{aligned} P n 3 m & =16.8 \\
\operatorname{Im} 3 m & =20.2\end{aligned}$ \\
\hline $30: 70$ & Ia3d cubic & 22.9 & $\operatorname{Im} 3 m$ cubic & 20.2 \\
\hline $40: 60$ & Pn3m cubic & $15.9-17.1$ & $\operatorname{Im} 3 m$ cubic & 20 \\
\hline $50: 50$ & $P n 3 m$ cubic & 18.6 & $\operatorname{Im} 3 m$ cubic & 18.9 \\
\hline $60: 40$ & Pn3m cubic & 18.6 & $\operatorname{Im} 3 m$ cubic & 22.2 \\
\hline $70: 30$ & Pn3m cubic & 17.4 & $\operatorname{Im} 3 m$ cubic & 22.8 \\
\hline $80: 20$ & Pn3m cubic & 18.2 & $\operatorname{Im} 3 m$ cubic & 23.1 \\
\hline
\end{tabular}

The results in Figure 5 indicate that at constant water content $(30 \mathrm{wt} \%, 60 \mathrm{wt} \%, 80$ $\mathrm{wt} \%$, or $95 \mathrm{wt} \%)$ the encapsulated quantity of FO favours the swelling of the selfassembled [FO:CU]/[MO:TPGS-PEG $\left.{ }_{1000}\right]$ supramolecular organization. The SAXS patterns shown in Figure 5A at $30 \mathrm{wt} \%$ water content are similar to those in Figure 4A. The increase of the FO weight fraction at growing FO:MO ratios (from 30:70 to 70:30 $(\mathrm{w} / \mathrm{w}))$ causes the swelling of the bicontinuous sponge phase before its transformation into a bicontinuous cubic phase for FO:MO ratio 80:20 (w/w)). Under these conditions, the excess water point was not reached yet below $80 \mathrm{wt} \%$ water content.

The universal rationale of the effect of various additives on the mean molecular shape and mean critical packing parameter of ideal amphiphilic mixtures, and the related effects of additives on lowering the curvature of the standard cubic phase of monoglycerides, has been discussed in detail by van't Hag et al. ${ }^{10}$ The investigated here fish oil (from menhaden source) is not an individual compound, which may form ideal self-assembled 
lipid mixtures with other lipids. For this reason, eventual CPP calculations based on the molecular shape concept, which might support the observed reduction of curvature of the host lipid cubic phase, would be of speculative character.

\section{Compositional Phase Diagram for Dual Curcumin- and Fish Oil-Loaded Lyotropic Liquid Crystalline Lipid Assemblies}

Figure 6 shows the phase diagram of the amphiphilic self-assembled systems composed of monoolein, MO-TPGS-PEG ${ }_{1000}$, fish oil and curcumin, [FO:CU]/[MO:TPGS$\left.\mathrm{PEG}_{1000}\right] /$ aqueous phase of $\mathrm{D}-(+)$ glucose (5 wt $\%$ in MilliQ water), which was determined at $22{ }^{\circ} \mathrm{C}$. The phase diagram was constructed using the structural SAXS analyses of the multicomponent samples prepared along the dilution lines (DL) indicated in Figure 2. A very rich phase behavior is deduced considering the various mesophases, which were identified by the SAXS measurements.

The obtained phase diagram is discussed in the series from the $\operatorname{DL}(0: 100)$ to the DL(90:10) dilution line. At high monoglyceride (MO) lipid and low water contents, a small region of a lamellar precursor phase is observed. With increasing water content up to $40 \mathrm{wt} \%$, a lamellar L $\alpha$ phase is obtained along the DL(0:100) dilution line (blue area in Figure 6). The formation of sponge phases occurs at compositions belonging to the other dilution lines (green domain in Figure 6) at increasing [FO:CU] content, but at low water contents (ranging from 10 to $40 \mathrm{wt} \%$ ). At higher water contents from 40 to $60 \mathrm{wt} \%$, the formation of a bicontinuous cubic phase (Ia3d space group) occurs along the DL(10:90), DL(20:80), DL(60:40), DL(70:30) and DL(80:20) dilution lines at decreasing 
[MO:TPGS-PEG ${ }_{1000}$ ] fractions. In the intermediate regions, the bicontinuous cubic phase (Ia3d space group) coexists with a sponge phase (yellow areas in Fig. 6). The decrease of the fish oil content allows the formation of a bicontinuous cubic Pn $3 m$ phase in the highwater content region from $70-90 \mathrm{wt} \%$ (orange domain in Fig. 6). The formation of the primitive cubic $\operatorname{Im} 3 m$ phase is observed in large excess of water and low oil content (pink area in Fig. 6).

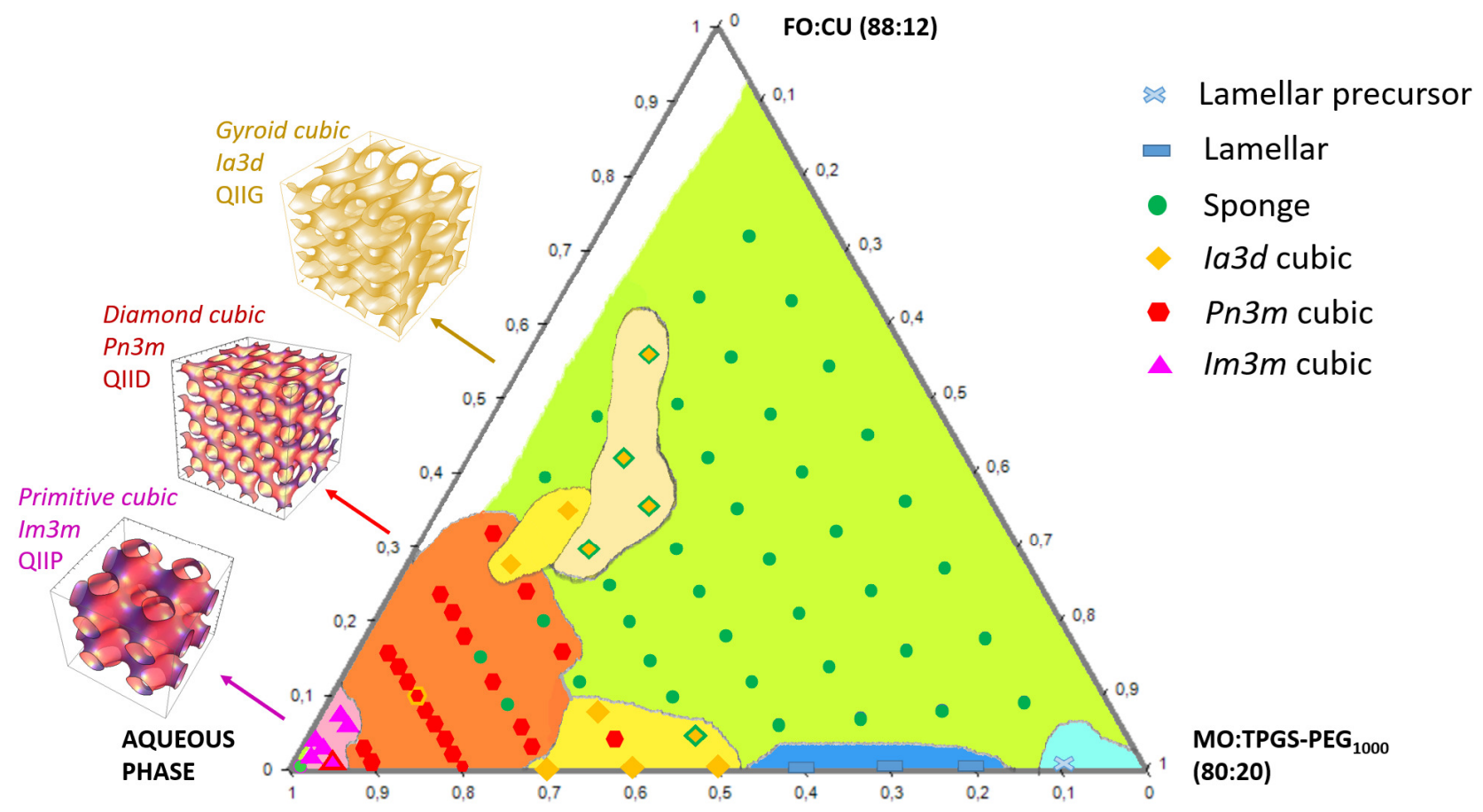

Figure 6. Ternary phase diagram of the MO/TPGS-PEG ${ }_{1000} / \mathrm{FO} / \mathrm{CU} /$ water system at temperature $22^{\circ} \mathrm{C}$ displaying the lipid compositional regions that yield cubic liquid crystalline phases of 3D topologies (cubic Im3m, cubic Pn3m, and cubic Ia3d space groups) as well as sponge and lamellar phases. The aqueous medium contains D-(+)glucose $(5 \mathrm{wt} \%)$. The shedding indicates the compositions with $\operatorname{Im} 3 \mathrm{~m}$ primitive cubic structure (pink), Pn3m double diamond cubic structure (red/orange), Ia3d gyroid cubic structure (yellow/beige), sponge (light green), lamellar (blue), and lamellar precursor 
(light blue) phases. The two-color symbols denote coexistences of mixed liquid crystalline phases.

For the investigated large number of samples below the excess water point, experimental drawbacks related to sample mixing/inhomogeneity, led to the observation of slightly anomalous phase behaviour of isolated samples. Sponge phase architecture (lacking long-range order of the bicontinuous lipid membranes) was attributed to these samples in the absence of well-defined Bragg diffraction peaks in the SAXS patterns. The isolated samples lacking long-range order, which are noticed in the red/orange and yellow/beige regions in the phase diagram (Figure 6), can be regarded also as cubic phase precursors.

\section{Structural and Morphological Characterization of Dispersed Liquid Crystalline Lipid Nanoparticles by Synchrotron SAXS and Cryo-TEM Imaging}

Dispersing of the bulk lyotropic phases, facilitated by the PEGylated amphiphile TPGS-PEG 1000 and mechanical agitation, produces liquid crystalline lipid nanoparticles with inner self-assembled structures (called cubosomes, spongosomes, hexosomes or

liposomes) in excess aqueous medium. ${ }^{6,9,11,28,42}$ We prepared aqueous dispersions of liquid crystalline lipid nanoparticles at eight weight ratios 25/75, 30/70, 40/60, 50/50, 60/40, 70/30, 80/20 and 90/10 (w/w \%) between fish oil and monoolein [FO:CU]/[MO:TPGS-PEG 1000$]$ at 95-99 wt\% water contents. The SAXS patterns of the dispersed MO/TPGS-PEG ${ }_{1000} / \mathrm{FO} / \mathrm{CU}$ lipid particles, containing low fractions of fish oil, displayed Bragg reflections of an inner primitive cubic lattice structure (Im3m space group) (Fig. 7A). The structural parameters determined by the SAXS analysis are 
presented in Table 4. In agreement with the SAXS data (Fig. 7A), the cryo-TEM images revealed the formation of cubosome type lipid nanoparticles (Fig. 7C). The SAXS patterns of the dispersed MO/TPGS-PEG ${ }_{1000} / \mathrm{FO} / \mathrm{CU}$ mixtures, which are rich in fish oil, showed scattering curves typical for bicontinuous sponge membranes with no periodic organization (Figs. 7B). The cryo-TEM images revealed the topology of the cubosome and spongosome nanoparticles loaded by high amounts of fish oil and phytochemical antioxidant (Figs. 7C and 7D).

The variety of lipid nanoparticle morphologies, which were present in the studied PEGylated lipid dispersions loaded with fish oil and phytochemical antioxidant are visualized in Figs. 7C-7E. They include monoolein-based cubosome and spongosome nanoparticles, double membrane vesicles, and vesicular precursors of bicontinuous liquid crystalline phases. The size distribution of the fish oil and curcumin-loaded cubosome and spongosome nanoparticles was studied by quasi-elastic light scattering (QELS) (Table 5). The results show the presence of two main populations, which represent the cubosomes and spongosome nanoparticles (with mean hydrodynamic diameters of about $250 \mathrm{~nm}-450 \mathrm{~nm}$ ) and their precursors (with hydrodynamic diameters of about $100 \mathrm{~nm}$ ) (Table 5). 

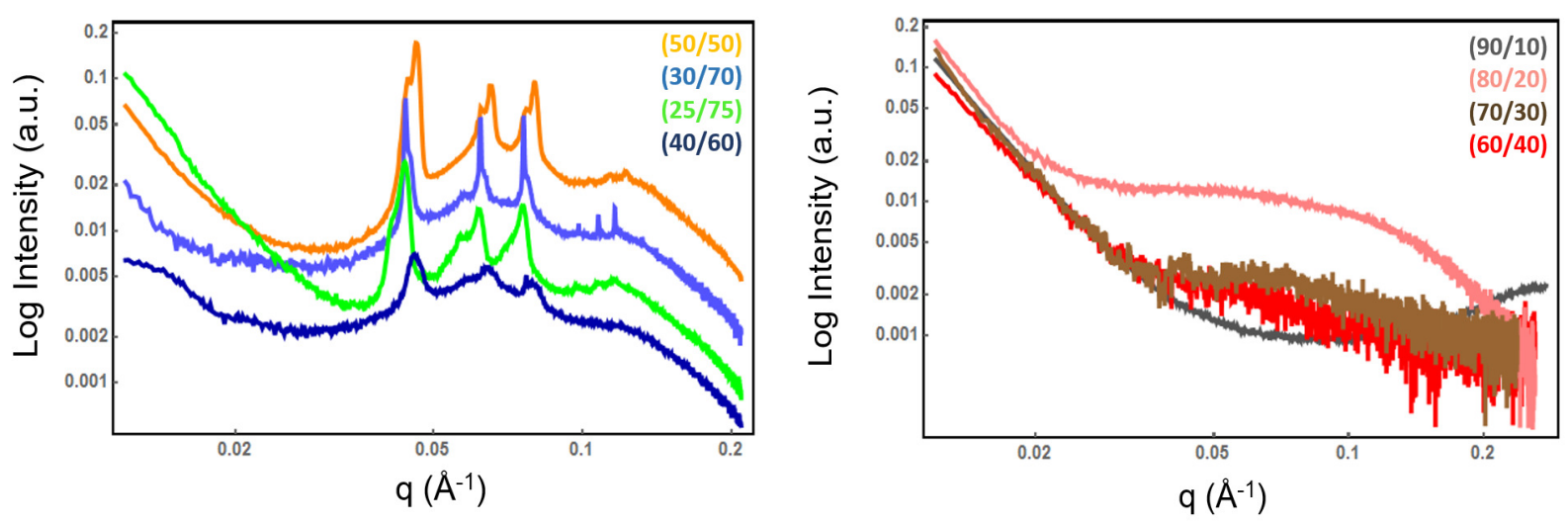

C

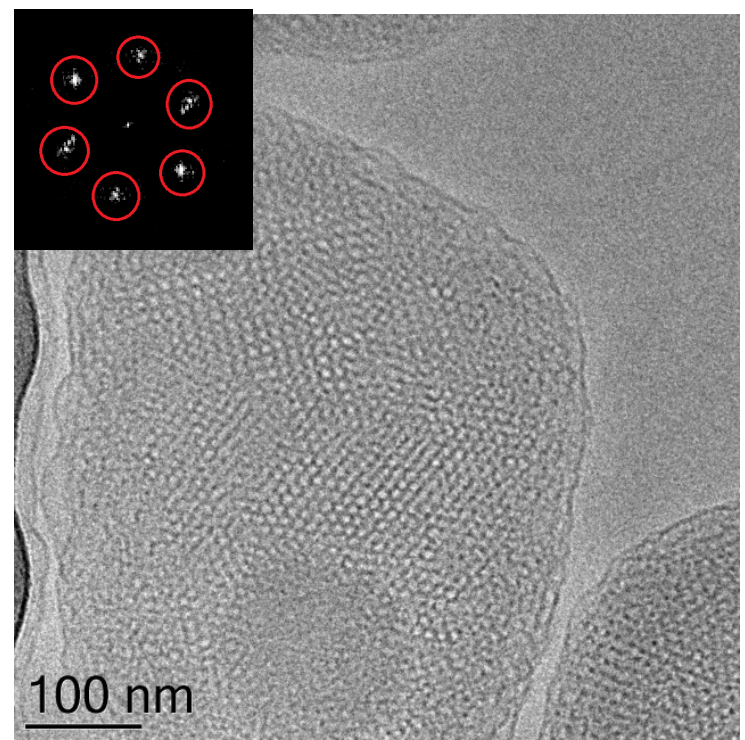

D

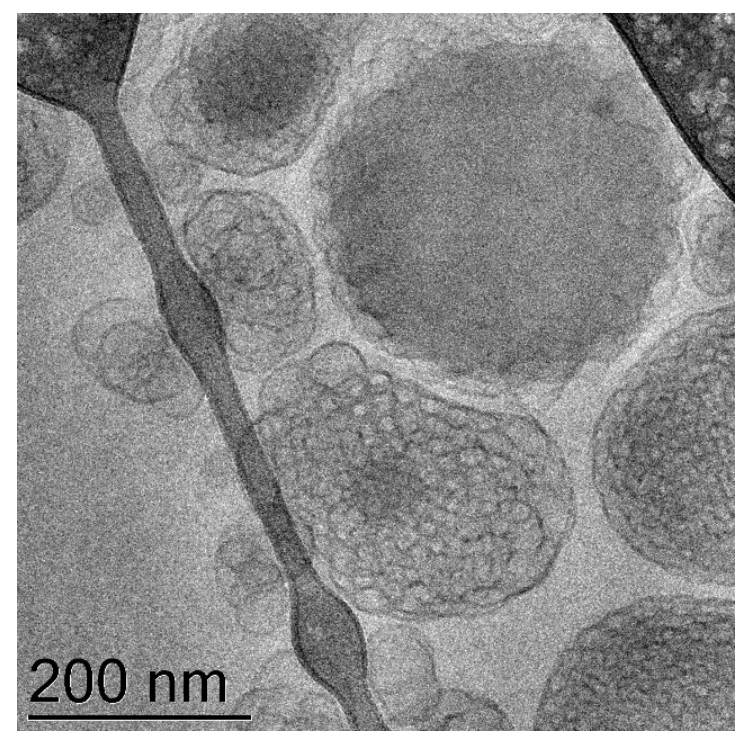

E

F
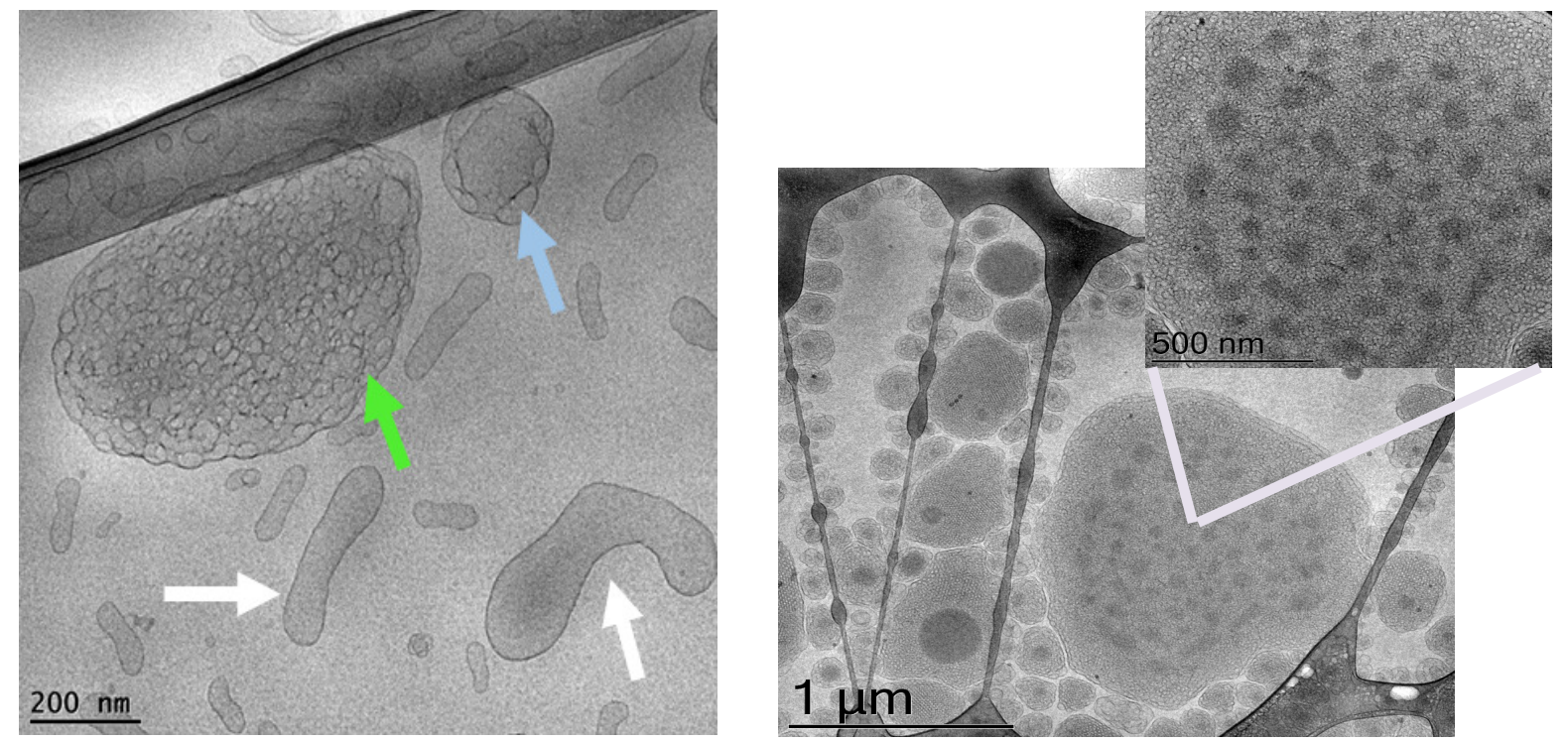
Figure 7. (A-B) SAXS patterns of liquid crystalline lipid nanoparticle dispersions obtained at varying fish oil/monoolein ratios [FO:CU]/[MO:TPGS-PEG $\left.{ }_{1000}\right](\mathrm{w} / \mathrm{w} \%)$ at $22^{\circ}$ C. (C-F) Cryo-TEM images of dispersed mixed assemblies showing (C) Cubosomal architectures with inner oil-rich domains. The inset shows the fast Fourier transform (FFT) of the image, which confirms the presence of cubic liquid crystalline organization in the inner structure of the lipid-based nanoparticles; (D) High oil-loaded sponge nanocarriers; (E) Double bilayer membrane containers (white arrows) in a coexistence with unilamellar vesicle precursors (blue arrow) as well as spongosome nanoparticles (green arrow); (F) Liquid crystalline lipid nanoparticles with encapsulated phytochemical antioxidant and fish oil. Inset: Magnified area showing the inner nanodomain organization of the dual-loaded lipid nanoparticles.

A cryo-TEM image of liquid crystalline lipid nanoparticles with dual-encapsulated bioactive ingredients is shown in Figure 7F. Lipid-based cubosomes and spongosomes involve multiple internal compartments, which represent a structural advantage enabling the encapsulation efficacy..$^{5-8,11-13,19-27,33}$ It has been suggested that encapsulated curcumin may increase the negative curvature of the polar/apolar interfaces of the lipid nanoassemblies and therefore may stabilize the cubic structure formation. ${ }^{43}$

Table 4. Internal cubic liquid crystalline structure type and unit cell lattice parameters of [FO:CU]/[MO:TPGS-PEG 1000$]$ self-assembled lipid nanoparticles dispersed in 95-99 $\mathrm{wt} \%$ aqueous environment determined by structural SAXS analysis of the data shown in Figure 7A. 


\begin{tabular}{|c|c|c|}
\hline $\begin{array}{c}\text { [FO:CU]/[MO:TPGS-PEG } \\
\text { ratio } \mathbf{~ ( w / w \% ) ~}\end{array}$ & LLC structures & $\begin{array}{c}\text { Lattice } \mathbf{a}_{(\mathbf{Q})} \\
(\mathbf{n m})\end{array}$ \\
\hline $50 / 50$ & Im3m cubic & 19.7 \\
\hline $30 / 70$ & Im3m cubic & 20.6 \\
\hline $25 / 75$ & Im3m cubic & 20.6 \\
\hline $40 / 60$ & Im3m cubic & 19.3 \\
\hline
\end{tabular}

Table 5. Hydrodynamic size determination of dual fish oil- and curcumin-loaded cubosome liquid crystalline lipid nanoparticles in excess aqueous phase (98 wt\%) by quasi-elastic light scattering (QELS).

\begin{tabular}{|c|c|c|}
\hline $\begin{array}{c}\text { [FO:CU]/[MO:TPGS-PEG } \\
\text { rao0] }\end{array}$ & $\begin{array}{c}\text { Mean hydrodynamic } \\
\text { particle diameter by } \\
\text { intensity distribution } \\
(\mathbf{n m})\end{array}$ & $\begin{array}{c}\text { Mean hydrodynamic } \\
\text { particle diameter by } \\
\text { volume distribution } \\
(\mathbf{n m})\end{array}$ \\
\hline $0 / 100$ & $51-255$ & $79-295$ \\
\hline $20 / 80$ & $106-255$ & $106-220$ \\
\hline $40 / 60$ & $122-395$ & $106-395$ \\
\hline $50 / 50$ & $106-396$ & $106-460$ \\
\hline
\end{tabular}


Controlled delivery of multiple active compounds is required for various pharmaceutical and nutraceutical applications. The overall efficacies of the obtained formulations will be an outcome of the encapsulation and release properties of the nanocarriers. Whereas the multicompartment structure of the lipidic cubosome and spongosome nanoparticles is advantageous for the enhanced encapsulation of bioactive molecules, the retention of the entrapped molecules and the multiple drug release could be hampered by the compartmentalized nanoparticle structure. In addition, drug release may trigger structural changes in the supramolecular organization of the nanocarriers. Therefore, future work should be envisioned to study the modulation of the release profiles through the multicompartment liquid crystalline lipid nanoparticle organization at varying multicomponent compositions.

Regarding the potential applications of the investigated dual-loaded nanoscale liquid crystalline lipid systems, various research directions may be envisioned towards new therapeutics or nutraceutics strategies. First, cubosomal curcumin has been suggested as an emergent opportunity for therapeutic innovation. ${ }^{43,55,60}$ As a multipurpose drug, the natural phytochemical curcumin displays antiviral, anti-proliferative, antioxidant, and neuroprotective activities. ${ }^{49,51}$ In addition, it can boost the PUFAs effects in strategies for prevention of disease progression through the use of nutraceutical formulations. ${ }^{58,62}$

Second, the class of polyunsaturated fatty acids (PUFAs) involves antiviral lipid molecules that may inactivate envelope viruses and inhibit coronavirus proliferation. The antiviral properties of naturally occurring fatty acids and their monoglycerides have been recognized since long time. ${ }^{99,100}$ However, the fact that monoglycerides may display equal capacity for viral inactivation, at 5 to 10 times lower concentrations than their 
corresponding fatty acids, ${ }^{99,100}$ has scarcely been exploited for clinical applications. Recently, lipid-targeted treatment of virus-infected cells has been suggested as a strategy for human Severe Acute Respiratory Syndrome Coronavirus (SARS-CoV-2) inhibition. ${ }^{101}$ Lipid-based nanoparticles are under advanced development as carriers for vaccine production to prevent the SARS-CoV-2 infection. ${ }^{102-105}$ The capacity of rapid safety evaluation and regulatory validation of controlled-release delivery carriers of anticoronavirus drugs and new vaccines makes the lipid-based nanotechnology a universal platform for advancement of the anti-SARS-CoV-2 research among other therapeutic applications. $^{102,105}$

Third, lipid nanoparticles loaded with natural phytochemical antioxidants represent strong interest for development of new treatments of neurodegenerative diseases. ${ }^{7,9,59,60,91}$ Taking into account that the pharmacological and therapeutic potential of marine-derived omega-3 polyunsaturated fatty acids and their clinical relevance are well underlined, ${ }^{47,73,79,91} \omega$-3 PUFAs could be used to impart synergistic effect in dual-loaded formulations.

Considering that the recognized antiviral activity of monoglycerides has not been exploited in the clinic yet, the reported here tunable 2D and 3D nanoscale topologies may serve as a platform for rapid development of (i) antiviral drug delivery systems and vaccine excipients, (ii) lipid-based formulations for multitarget therapies, and (iii) natural adjunctive therapeutics for various health applications using phytochemical antioxidants in combination therapies of inflammatory, cardiovascular and neurodegenerative diseases; and (iv) novel nutraceutical formulations involving natural plant-based antioxidant substances and marine-derived $\omega$-3 PUFAs. Therefore, the obtained here new 
knowledge about the PEGylated liquid crystalline nanostructured assemblies should contribute to fabrication of more stable and safe multicomponent green delivery systems.

\section{CONCLUSION}

Sustainable development of modern multi-targeted nutraceuticals and pharmaceuticals against various severe diseases, including viral infections, inflammation, neurodegenerative and cardio-vascular disorders, requires novel structural knowledge about phase diagrams enabling the preparation of switchable liquid crystalline nanocarriers of advanced properties. Solubility, encapsulation and enhanced loading of bioactive phytochemicals and natural functional lipids are major issues in the design of innovative delivery formulations with increased bioavailability. In the context of preventive and supportive therapies using combinations with nutraceuticals, natural plantbased antioxidant compounds, such as curcumin, and marine-derived (fish-oil) PUFAs can boost the effects of the co-administered active compounds and drugs in various antiviral, cardiovascular or neurodegenerative targeting mechanisms.

We designed PEGylated dual-loaded liquid crystalline (cubosome and spongosome) lipid nanoparticle formulations suitable for large-scale cost-effective production. They contain natural antiviral compounds and can serve for encapsulation of additional hydrophobic or hydrophilic active substances to target various disease mechanisms. Thus, the obtained nanoscale cubosome and spongosome type carrier systems should be of interest for multi-compound loading. The reported structural results revealed that loading with fish oil leads to a composition-mediated switch between different liquid crystalline nanostructures. Interestingly, a metastable low-temperature cubic phase was observed 
with bulk PEGylated assemblies prepared with 5 wt\% D-(+)-glucose aqueous medium. The multicompartment crystalline organization may impact the mechanical and release properties of the delivery carriers.

The constructed phase diagram characterizes various polymorphic states at different hydration levels. Based on the presented SAXS results, PEGylated multi-loaded sustained release formulations can quickly be developed. In fact, deeper understanding of the structure and phase behavior of mixed pharmaceutical compositions is a key to greatly enhancing the success rate of the drug delivery strategies. Evaluating the stability of the hydrated structures is particularly important because changes in the hydration state may cause alterations of the physicochemical properties of the carrier systems. The acquired knowledge about the PEGylated mixed polymorphic liquid crystalline assemblies and structures may contribute for improving the outcome of combination treatments as well as of the development of vaccine carriers.

\section{MATERIALS AND METHODS}

\section{Materials}

Monoolein (MO) (purity > 99\%) was obtained from Hampton Research. Fish oil from menhaden (crude source of $\omega$-3 fatty acids), D- $\alpha$-tocopheryl poly(ethylene glycol)1000 succinate $\left(\mathrm{TPGS}-\mathrm{PEG}_{1000}\right.$ ), curcumin (purity $>66 \%$ in the curcuminoid mixture), and D(+)-glucose (dextrose, purity $\geq 99.5 \%$ ) were purchased from Sigma-Aldrich.

Design of Self-Assembled Nanocarriers for Loading of Fish oil and Curcumin 
The compositions of the investigated self-assembled MO/TPGS-PEG ${ }_{1000} / \mathrm{FO} / \mathrm{CU}$ systems are chosen from the phase diagram presented in Figure 2. Ten dilution lines (DL), denoted as DL 10:90, DL 20:80, DL 30:70, DL 40:60, DL 50:50, DL 60:40, DL 70:30, DL 80:20 and DL 90:10 (w/w \%), are defined in order to characterize the lyotropic behavior of the multicomponent amphiphilic mixtures of therapeutic significance. The water-rich region corresponds to dispersions of nanocarriers in excess aqueous medium. The lipid-rich region corresponds to bulk liquid crystalline assemblies. About 200 samples were prepared for SAXS measurements. The quantity of MO was minimum 10 mg per sample. Depending on the hydration level, the volume of the aqueous phase varied from $0.01 \mathrm{~mL}$ to $1 \mathrm{~mL}$ for the different sample preparations.

Preparation of Bulk and Dispersed Liquid Crystalline Systems

The lipid nanoparticles were prepared by the method of hydration of a lyophilized thin lipid film followed by physical agitation in excess aqueous phase..$^{9,28,34,43,59}$ The lipid monoolein (MO), the amphiphilic stabilizer TPGS-PEG ${ }_{1000}$, fish oil (FO), and curcumin (CU) were weighed, dissolved in chloroform and mixed at desired proportions. The samples were prepared at room temperature at ten different fish oil/monoolein weight ratios of 10:90, 20:80, 30:70, 40:60, 50:50, 60:40, 70:30, 80:20, and 90:10 (w/w \%). The solvent was evaporated under a stream of a nitrogen gas for $1 \mathrm{~h}$ at room temperature to create a thin film lipid sample. The samples were lyophilized overnight under cooling to remove the excess solvent. This step was followed by the hydration of the thin film samples by a solution of $\mathrm{D}(+)$-glucose $(5 \mathrm{wt} \%$ ) (prepared using Milli-Q water) for $24 \mathrm{~h}$ 
at room temperature. Finally, the samples were vortexed vigorously at room temperature in cycles during $15 \mathrm{~min}$.

Synchrotron Small Angle X-Ray Scattering (SAXS)

Characterization of the lyotropic liquid crystalline structures was performed using SAXS experiments at the SWING beamline of synchrotron SOLEIL (Saint Aubin, France). ${ }^{106}$ The sample-to-detector distance was $3 \mathrm{~m}$. The patterns were recorded with a two-dimensional EigerX 4-M detector (DECTRIS Ltd.) at $12 \mathrm{keV}$, allowing measurements in the $q$-range from 0.00426 to $0.37 \AA^{-1}$. The $q$-vector was defined as $q=$ $(4 \pi / \lambda) \sin \theta$, where $2 \theta$ is the scattering angle. The synchrotron radiation wavelength was $\lambda$ $=1.033 \AA$. The $q$-range calibration was done using a standard sample of silver behenate $(d=58.38 \AA)$. The temperature was $22{ }^{\circ} \mathrm{C}$. The investigated samples were filled in capillaries with a diameter of $1.5 \mathrm{~mm}$ and were sealed by paraffin wax. They were oriented in front of the X-ray beam $\left(25 \times 375 \mu \mathrm{m}^{2}\right)$ using a designed holder for multiple capillaries positioning (X, Y, Z). Exposure times of $500 \mathrm{~ms}$ (for bulk lipid samples) or $1 \mathrm{~s}$ (for diluted nanoparticles) were used. No radiation damage was observed at these exposure times. Scattering patterns of an empty capillary and a capillary filled with MilliQ water were recorded for intensity background subtraction. Data processing of the recorded 2D images was performed by the FOXTROT software. ${ }^{43,102}$ An average of three spectra per capillary was acquired.

The lattice parameters of the liquid crystalline phases were derived from the Bragg peaks detected in the X-ray diffraction patterns. The lattice parameter $a$ is determined by $a=d\left(h^{2}+k^{2}+l^{2}\right)^{1 / 2}$ for the cubic phases, where $d$ is defined by Bragg's law $d=2 \pi / q$ 
and is the repeat distance between the scattering planes. The assigned reflections were fitted through the Miller indexes according to the following relationships:

$a / d=1,2,3, \ldots \quad$ for structures with a lamellar spacing

$(a / d)^{2}=2,3,4,6,8,9,10,12,14, \ldots \quad$ for the Pn3m space group (Diamond cubic, D)

$(a / d)^{2}=2,4,6,8,10,12,14,16,18,20,22 \ldots$ for the $\operatorname{Im} 3 m$ space group (Primitive cubic, P)

$(a / d)^{2}=6,8,14,16,20,22,24,26, \ldots \quad$ for the Ia3d space group (Gyroid cubic, G)

\section{Nanoparticle size determination}

The particle size distribution was determined by means of a Nano-ZS90 device (Malvern Instruments) collecting the intensity of the scattered light at an angle of $90^{\circ}$ with regards to the incident laser beam. The hydrodynamic diameters were determined by the software using Stoke-Einstein's relation to describe the Brownian motion of the particles. The samples were diluted to $1 / 10$ in Milli-Q water in order to ensure Brownian motion conditions. The refractive index and viscosity of MilliQ water were equal to 1.330 and 0.8872 , respectively. Each analysis was a result of three consecutive measurements carried out at $25{ }^{\circ} \mathrm{C}$. The Zetasizer software produces reports about the particle size distribution expressed as QELS intensity, volume, or number size distributions. To get more insight about the studied samples, the mean hydrodynamic 
diameters were determined from both the intensity and volume distributions. The recorded intensity of the volume distribution indicated that the larger particles $(250-400$ $\mathrm{nm}$ ) with inner liquid crystalline organization prevail over the population of small precursors $(50-100 \mathrm{~nm})$, which results from the sonication process.

\section{Cryogenic transmission electron microscopy (cryo-TEM)}

For cryo-TEM investigation, a sample droplet of $2 \mu \mathrm{L}$ was placed on a lacey carbon film covered copper grid (Science Services, Munich, Germany), which was hydrophilized by glow discharge (Solarus, Gatan, Munich, Germany) for 30s. Most of the liquid was then removed with blotting paper, leaving a thin film stretched over the lace holes. The specimen was instantly shock frozen by rapid immersion into liquid ethane and cooled to approximately $90 \mathrm{~K}$ by liquid nitrogen in a temperature and humidity controlled freezing unit (Leica EMGP, Wetzlar, Germany). The temperature and humidity were monitored and kept constant in the chamber during all sample preparation steps. The specimen was inserted into a cryo-transfer holder (CT3500, Gatan, Munich, Germany) and transferred to a Zeiss EM922 Omega energy-filtered TEM (EFTEM) instrument (Carl Zeiss Microscopy, Jena, Germany). Examinations were carried out at temperatures around 90 K. The TEM instrument was operated at an acceleration voltage of $200 \mathrm{kV}$. Zero-lossfiltered images $(\mathrm{DE}=0 \mathrm{eV})$ were taken under reduced dose conditions $\left(100-1000 \mathrm{e} / \mathrm{nm}^{2}\right)$. The images were recorded digitally by a bottom-mounted charge-coupled device (CCD) camera system (Ultra Scan 1000, Gatan, Munich, Germany) and combined and processed with a digital imaging processing system (Digital Micrograph GMS 1.9, Gatan, Munich, Germany). The sizes of the investigated nanoparticles were in the range or below the film 
thickness and no deformations were observed. The images were taken very close to focus or slightly under the focus (some nanometers) due to the contrast enhancing capabilities of the in-column filter of the employed Zeiss EM922 Omega. In EFTEMs, the deep underfocused images can be totally avoided.

\section{Author Contributions}

The manuscript was prepared through contributions of all authors. Experimental investigation: M.R., B.A., M.D., S.E., K.K., A.A.; Instrument management and software: T.B., M.D.; Analysis and data processing: M.R., B.A., M.D., A.A.; Funding and materials: B.A.; Writing - Original draft: M.R., B.A., A.A.; Writing - review \& editing: A.A.; Conceptualization and Supervision: A.A.

\section{Funding Sources}

The performed research was funded by the "IDI 2017" project of the IDEX ParisSaclay/ANR-11-IDEX-0003-02 and the projects "Structural Dynamics of Biomolecular Systems" (ELIBIO) (CZ.02.1.01/0.0/0.0/15_003/0000447) and "Advanced research using high-intensity laser produced photons and particles" (CZ.02.1.01/0.0/0.0/16_019/0000789) from the European Regional Development Fund. B.A. obtained also a financial support from the collaborative project with JINR, Dubna, Russia (3+3 program, No. 204, item 27 from 25.03.2020). K.K. acknowledges the financial support from the Czech Academy of Sciences (Grant number: MSM100101901). 


\section{ACKNOWLEDGMENT}

We gratefully acknowledge the allocation of beam time at Synchrotron SOLEIL (Saint Aubin, France) through the projects 20170933, 20181489, and 20201321, and all scientific and technical support at the SWING beamline. M.D. is supported by the collaborative research center SFB840 of the German Science Foundation DFG. AA acknowledges a membership in CNRS GDR2088 BIOMIM research network.

\footnotetext{
ABBREVIATIONS

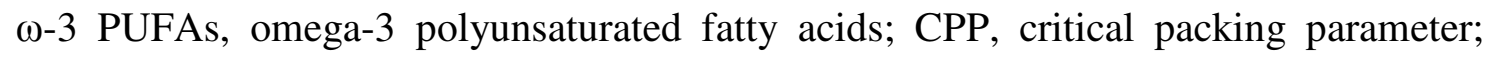
cryoTEM, cryogenic transmission electron microscopy; CU, curcumin; DHA, docosahexaenoic acid; DL, dilution line; EPA, eicosapentaenoic acid; FO, fish oil; LLC, lyotropic liquid crystalline; LCNPs, liquid crystalline nanoparticles; MO, monoolein; SAXS, small-angle X-ray scattering; TPGS-PEG 1000 , D- $\alpha$-tocopheryl poly (ethylene glycol) 1000 succinate.
} 


\section{REFERENCES}

(1) Chen, X.; Yi, Z.; Chen, G.; Ma, X.; Su, W.; Deng, Z.; Ma, L.; Tong, Q.; Ran, Y.; Xudong $\mathrm{Li}, \mathrm{X}$. Carrier-enhanced photodynamic cancer therapy of self-assembled green tea polyphenol-based nanoformulations. ACS Sustainable Chem. Eng. 2020, 8, 43, 1637216384. DOI: 10.1021/acssuschemeng.0c06645.

(2) Clemente, I.; Falsini, S.; Di Cola, E.; Fadda, G.C.; Gonnelli, C.; Spinozzi, F.; BaciaVerloop, M.; Grillo, I.; Ristori, S. Green nanovectors for phytodrug delivery: In-depth structural and morphological characterization. ACS Sustainable Chem. Eng. 2019, 7 , 12838-12846. DOI: 10.1021/acssuschemeng.9b01748.

(3) Elabbadi, A.; Jerri, H.A.; Ouali, L.; Erni, P. Sustainable delivery systems: Retention of model volatile oils trapped on hybrid calcium carbonate microparticles. ACS Sustainable Chem. Eng. 2015, 3, 9, 2178-2186. DOI: 10.1021/acssuschemeng.5b00446.

(4) Glatter, O.; Salentinig, S. Inverting structures: From micelles via emulsions to internally self-assembled water- and oil-continuous nanocarriers. Curr. Opinion Colloid Interface Sci. 2020, 49, 82-93. DOI:10.1016/j.cocis.2020.05.003.

(5) Angelova, A.; Angelov, B.; Mutafchieva, R.; Lesieur, S.; Couvreur, P. Self-assembled multicompartment liquid crystalline lipid carriers for protein, peptide, and nucleic acid drug delivery. Acc Chem Res 2011, 44,147-56. DOI: 10.1021/ar100120v.

(6) Alfredsson, V.; Lo Nostro, P.; Ninham, B.; Nylander, T. Morphologies and structure of brain lipid membrane dispersions. Front. Cell Dev. Biol. 2021, 9, 675140. DOI: 10.3389/fcell.2021.675140.

(7) Angelova, A.; Angelov, B. Dual and multi-drug delivery nanoparticles towards neuronal survival and synaptic repair. Neural Regeneration Res. 2017, 12, 886-889. DOI: 10.4103/1673-5374.208546.

(8) Yaghmur, A.; $\mathrm{Mu}, \mathrm{H}$. Recent advances in drug delivery applications of cubosomes, hexosomes, and solid lipid nanoparticles. Acta Pharmaceutica Sinica B 2021, 11, 871-885. DOI: 10.1016/j.apsb.2021.02.013.

(9) Angelova, A.; Drechsler, M.; Garamus, V.M.; Angelov, B. Pep-lipid cubosomes and vesicles compartmentalized by micelles from self-assembly of multiple neuroprotective building blocks including a large peptide hormone PACAP-DHA. ChemNanoMat 2019, 5, 1381-1389. DOI: 10.1002/cnma.201900468.

(10) van't Hag, L.; Gras, S.L.; Conn, C.E.; Drummond, C.J. Lyotropic liquid crystal engineering moving beyond binary compositional space - ordered nanostructured amphiphile self-assembly materials by design. Chem. Soc. Rev. 2017, 46, 2705-2731. DOI: $10.1039 / \mathrm{c} 6 \mathrm{cs} 00663 \mathrm{a}$.

(11) Angelova, A.; Garamus, V.M.; Angelov, B.; Tian, Z.; Li, Y.; Zou, A. Advances in structural design of lipid-based nanoparticle carriers for delivery of macromolecular drugs, phytochemicals and anti-tumor agents. Adv. Colloid Interface Sci. 2017, 249, 331-345. DOI: 10.1016/j.cis.2017.04.006. 
(12) Yaghmur, A.; Tran, B.V.; Moghimi, S.M. Non-lamellar liquid crystalline nanocarriers for thymoquinone encapsulation. Molecules 2019, 25, 16. DOI: 10.3390/molecules25010016.

(13) Kulkarni, C.V. ; Vishwapathi, V.K.; Quarshie, A.; Moinuddin, Z.; Page, J. ; Kendrekar, P.; Mashele, S.S. Self-assembled lipid cubic phase and cubosomes for the delivery of a model drug (aspirin). Langmuir, 2017, 33, 9907-9915. DOI: 10.1021/acs.langmuir.7b02486

(14) Chang, D.P.; Barauskas, J.; Dabkowska, A.P.; Wadsäter, M.; Tiberg, F.; Nylander, T. Non-lamellar lipid liquid crystalline structures at interfaces. Adv Colloid Interface Sci. 2015, 222, 135-147. DOI: 10.1016/j.cis.2014.11.003.

(15) Angelov, B.; Angelova, A.; Mutafchieva, R.; Lesieur, S.; Vainio, U.; Garamus, V.M.; Jensena, G.V.; Pedersena, J.S. SAXS investigation of a cubic to a sponge (L-3) phase transition in self-assembled lipid nanocarriers. Phys. Chem. Chem. Phys. 2011, 13, 30733081. DOI: $10.1039 / \mathrm{c0cp} 01029 \mathrm{~d}$.

(16) Mertins, O.; Mathews, P.D.; Angelova, A. Advances in the design of pH-sensitive cubosome liquid crystalline nanocarriers for drug delivery applications. Nanomaterials (Basel). 2020, 10, 963. DOI: 10.3390/nano10050963.

(17) Pilkington, C.P.; Seddon, J.M.; Elani, Y. Microfluidic technologies for the synthesis and manipulation of biomimetic membranous nano-assemblies. Physical Chemistry Chemical Physics 2021, 23, 3693-3706. DOI: 10.1039/d0cp06226j.

(18) Tan, A.; Lam, Y.Y.; Sun, X; Boyd, B. Monocytic cell-induced phase transformation of circulating lipid-based liquid crystalline nanosystems. Materials (Basel). 2020, 13, 1013. DOI: $10.3390 / \mathrm{ma13041013.}$

(19) Yaghmur, A. Nanoencapsulation of food ingredients by cubosomes and hexosomes, in Lipid-Based Nanostructures for Food Encapsulation Purposes. Ed. S. M. Jafari, Elsevier Book Series, London, 2019, 483-522. DOI: 10.1016/B978-0-12-815673-5.00012-X.

(20) Boge, L.; Hallstensson, K.; Ringstad, L.; Johansson, J.; Andersson, T.; Davoudi, M.; Larsson, P.T.; Mahlapuu, M.; Håkansson, J.; Andersson, M. Cubosomes for topical delivery of the antimicrobial peptide LL-37. Eur J Pharm Biopharm. 2019,134, 60-67. DOI: 10.1016/j.ejpb.2018.11.009.

(21) Faria, A.R.; Silvestre, O.F.; Maibohm, C.; Adão, R.M.R.; Silva, B.F.B.; Nieder. J.B. Cubosome nanoparticles for enhanced delivery of mitochondria anticancer drug elesclomol and therapeutic monitoring via sub-cellular $\mathrm{NAD}(\mathrm{P}) \mathrm{H}$ multi-photon fluorescence lifetime imaging. Nano Res. 2019, 12, 991-998. DOI: 10.1007/s12274-0182231-5.

(22) Elnaggar, Y.S.; Etman, S.M.; Abdelmonsif, D.A.; Abdallah, O.Y. Novel piperine-loaded Tween-integrated monoolein cubosomes as brain-targeted oral nanomedicine in Alzheimer's disease: pharmaceutical, biological, and toxicological studies. Int $J$ Nanomedicine. 2015, 10, 5459-5473. DOI: 10.2147/ijn.s87336.

(23) Fong, W.K.; Negrini, R.; Vallooran, J.J.; Mezzenga, R.; Boyd, B.J. Responsive selfassembled nanostructured lipid systems for drug delivery and diagnostics. J Colloid Interface Sci. 2016, 484, 320-339. DOI: 10.1016/j.jcis.2016.08.077. 
(24) Ramalheiro, A.; Paris, J.L.; Silva, B.F.B.; Pires, L.R., Rapidly dissolving microneedles for the delivery of cubosome-like liquid crystalline nanoparticles with sustained release of rapamycin, Int. J. Pharm., 2020, 591, 119942. DOI: 10.1016/j.ijpharm.2020.119942.

(25) Avachat, A.M.; Parpani, S.S. Formulation and development of bicontinuous nanostructured liquid crystalline particles of efavirenz. Colloids Surf B Biointerfaces. 2015, 126, 87-97. DOI: 10.1016/j.colsurfb.2014.12.014.

(26) Zhang, L.; Li, J.; Tian, D. et al. Theranostic combinatorial drug-loaded coated cubosomes for enhanced targeting and efficacy against cancer cells. Cell Death Dis, 2020, 11, 1. DOI: 10.1038/s41419-019-2182-0.

(27) Wu, H.; Li, J.; Zhang, Q.; Yan, X.; Guo, L.; Gao, X.; Qiu, M.; Jiang, X.; Lai, R.; Chen, H. A novel small Odorranalectin-bearing cubosomes: preparation, brain delivery and pharmacodynamic study on amyloid- $\beta_{25-35}$-treated rats following intranasal administration. Eur $J$ Pharm Biopharm. 2012, 80, 368-378. DOI: 10.1016/j.ejpb.2011.10.012.

(28) Angelova, A.; Angelov, B.; Drechsler, M.; Bizien, T.; Gorshkova, Y.E.; Deng Y. Plasmalogen-based liquid crystalline multiphase structures involving docosapentaenoyl derivatives inspired by biological cubic membranes. Front. Cell Dev. Biol. 2021, 9, 617984. DOI: 10.3389/fcell.2021.617984.

(29) Younus, M.; Prentice, R.N.; Clarkson, A.N.; Boyd, B.J. Rizwan, S.B. Incorporation of an endogenous neuromodulatory lipid, oleoylethanolamide, into cubosomes: nanostructural characterization. Langmuir 2016, 32, 8942-8950. DOI: 10.1021/acs.langmuir.6b02395.

(30) Kulkarni, C.V.; Wachter, W.; Iglesias-Salto, G.; Engelskirchen, S.; Ahualli, S. Monoolein: a magic lipid? Phys. Chem. Chem. Phys. 2011, 13, 3004-3021. DOI: 10.1039/c0cp01539c.

(31) Rosa, A.; Murgia, S.; Putzu, D,; Meli, V., Falchi, A.M. Monoolein-based cubosomes affect lipid profile in HeLa cells. Chem Phys Lipids. 2015, 191, 96-105. DOI: 10.1016/j.chemphyslip.2015.08.017.

(32) Mierzwa, M.; Cytryniak, A.; Krysiński, P.; Bilewicz, R. Lipidic liquid crystalline cubic phases and magnetocubosomes as methotrexate carriers. Nanomaterials (Basel). 2019, 9, 636. DOI: $10.3390 /$ nano9040636.

(33) Ali, M.A.; Kataoka, N.; Ranneh, A.H.; Iwao, Y.; Noguchi, S.; Oka, T.; Itai, S. Enhancing the solubility and oral bioavailability of poorly water-soluble drugs using monoolein cubosomes. Chem Pharm Bull (Tokyo). 2017, 65, 42-48. DOI: 10.1248/cpb.c16-00513.

(34) Israelachvili, J.N.; Mitchell, D.J.; Ninham, B. Theory of self-assembly of hydrocarbon amphiphiles into micelles and bilayers. J. Chem. Soc. Faraday Trans. 2 1976, 72, 15251568. DOI: $10.1039 / \mathrm{F} 29767201525$

(35) Hyde, S.T.; Andersson, S.; Ericsson, B.; Larsson, K.; Kristallogr, Z. A cubic structure consisting of a lipid bilayer forming an infinite periodic minimum surface of the gyroid type in the glycerol monooleate-water system. Zeitschrift für Krist 1984, 168:213-219. DOI: 10.1524/zkri.1984.168.14.213. 
(36) Briggs, J.; Qiu, H.; Caffrey, M. The temperature-composition phase diagram and mesophase structure characterization of the monoolein/water system. J. Phys. II 1996, 6, 723-751. DOI: 10.1016/S0006-3495(94)80632-0.

(37) Qiu, H.; Caffrey, M. The phase diagram of the monoolein/water system: metastability and equilibrium aspects. Biomaterials 2000, 21, 223-234. DOI: 10.1016/S01429612(99)00126-X.

(38) Lutton, E.S. Phase behavior of aqueous systems of monoglycerides. J Am Oil Chem Soc. 1965, 42, 1068-1070. DOI: 10.1007/BF02636909

(39) Angelov, B.; Angelova, A.; Garamus, V.M.; Drechsler, M.; Willumeit, R.; Mutafchieva, R.; Štěpánek, P.; Lesieur, S. Earliest stage of the tetrahedral nanochannel formation in cubosome particles from unilamellar nanovesicles. Langmuir 2012, 28, 16647-16655. DOI: $10.1021 / 1 \mathrm{la} 302721 \mathrm{n}$

(40) Angelov, B.; Angelova, A.; Vainio, U.; Garamus, V.M.; Lesieur, S.; Willumeit, R.; Couvreur, P. Long-living intermediates during a lamellar to a diamond-cubic lipid phase transition: a small-angle X-ray scattering investigation. Langmuir 2009, 25, 3734-3742. DOI: $10.1021 / 1 \mathrm{a} 804225 \mathrm{j}$

(41) Nilsson, C.; Ostergaard, J.; Larsen, S.W.; Larsen, C.; Urtti, A.; Yaghmur, A. PEGylation of phytantriol-based lyotropic liquid crystalline particles-the effect of lipid composition, PEG chain length, and temperature on the internal nanostructure. Langmuir 2014, 30, 6398-6407. DOI: 10.1021/la501411w

(42) Angelov, B.; Angelova, A.; Filippov, S.K.; Drechsler, M.; Stepanek, P.; Lesieur, S. Multicompartment lipid cubic nanoparticles with high protein upload: Millisecond dynamics of formation. ACS Nano 2014, 8, 5216-5226. DOI: 10.1021/nn5012946.

(43) Rakotoarisoa, M.; Angelov, B.; Espinoza, S.; Khakurel, K.; Bizien, T.; Angelova, A. Cubic liquid crystalline nanostructures involving catalase and curcumin: BioSAXS study and catalase peroxidatic function after cubosomal nanoparticle treatment of differentiated SH-SY5Y cells. Molecules. 2019, 24, 3058. DOI: 10.3390/molecules24173058.

(44) Zahedipour, F.; Hosseini, S.A.; Sathyapalan, T.; Majeed, M.; Jamialahmadi, T.; AlRasadi, K.; Banach, M.; Sahebkar, A. Potential effects of curcumin in the treatment of COVID-19 infection. Phytotherapy Research, 2020, 34, 2911-2920. DOI: 10.1002/ptr.6738.

(45) Liu, Z; Y Ying, Y. The inhibitory effect of curcumin on virus-induced cytokine storm and its potential use in the associated severe pneumonia. Front. Cell Dev. Biol. 2020, 8, 479. DOI: $10.3389 /$ fcell.2020.00479.

(46) Jennings, M.R.; Parks, R.J. Curcumin as an antiviral agent. Viruses. 2020, 12, 1242. DOI: 10.3390/v12111242.

(47) Ahmed, T.; Gilani, A.-H. Therapeutic potential of turmeric in Alzheimer's disease: Curcumin or curcuminoids? Phytother Res. 2013, 28, 517-525. DOI: 10.1002/ptr.5030. 
(48) Kuszewski, J.C.; Howe, P.R.C.; Wong, R.H.X. Evaluation of cognitive performance following fish-oil and curcumin supplementation in middle-aged and older adults with overweight or obesity. $J$ Nutr. 2020, 150, 3190-3199. DOI: 10.1093/jn/nxaa299.

(49) Zielińska, A.; Alves, H.; Marques, V.; Durazzo, A.; Lucarini, M.; Alves, T.F.; Morsink, M.; Willemen, N.; Eder, P.; Chaud, M.V.; Severino, P.; Santini, A.; Souto, E.B. Properties, extraction methods, and delivery systems for curcumin as a natural source of beneficial health effects. Medicina 2020, 56, 336. DOI: 10.3390/medicina56070336.

(50) Gupta, S. C.; Patchva, S.; Aggarwal, B. B. Therapeutic roles of curcumin: lessons learned from clinical trials. AAPS J. 2013, 15, 195-218. DOI: 10.1208/s12248-012-9432-8.

(51) Serafini, M. M.; Catanzaro, M.; Rosini, M.; Racchi, M.; Lanni, C. Curcumin in Alzheimer's disease: can we think to new strategies and perspectives for this molecule? Pharmacol. Res. 2017, 124, 146-155. DOI: 10.1016/j.phrs.2017.08.004.

(52) Brondino, N.; Re, S.; Boldrini, A.; Cuccomarino, A.; Lanati, N.; Barale, F.; Politi, P. Curcumin as a therapeutic agent in dementia: a mini systematic review of human studies. Sci. World J. 2014, 2014, 174282. DOI: 10.1155/2014/174282.

(53) Wu, J.; Li, Q.; Wang, X.; Yu, S.; Li, L.; Wu, X.; Chen, Y.; Zhao, J.; Zhao, Y. Neuroprotection by curcumin in ischemic brain injury involves the Akt/Nrf2 pathway. PLoS One 2013, 8, 59843. DOI: 10.1371/journal.pone.0059843.

(54) Esposito, E.; Ravani, L.; Mariani, P.; Contado, C.; Drechsler, M.; Puglia C.; Cortesi, R. Curcumin containing monoolein aqueous dispersions: A preformulative study. Mater Sci Eng C 2013, 33, 4923-34. DOI: 10.1016/j.msec.2013.08.017.

(55) Chang, C.; Meikle, T.G.; Drummond, C.J.; Yang, Y.; Conn, C.E. Comparison of cubosomes and liposomes for the encapsulation and delivery of curcumin. Soft Matter 2021, 17, 3306-3313. DOI: 10.1039/d0sm01655a.

(56) Soleimani, V.; Sahebkar, A.; Hosseinzadeh, H. Turmeric (Curcuma longa) and its major constituent (curcumin) as nontoxic and safe substances: Review. Phytother Res. 2018, 32, 985-995. DOI: 10.1002/ptr.6054.

(57) Anand, P.; Kunnumakkara, A. B.; Newman, R. A.; Aggarwal, B. B. Bioavailability of curcumin: problems and promises. Mol. Pharm. 2007, 4, 807-818. DOI: $10.1021 / \mathrm{mp} 700113 \mathrm{r}$.

(58) Zou, L.; Zheng, B.; Zhang, R.; Zhang, Z.; Liu, W.; Liu, C.; Zhang, G.; Xiao, H.; McClements, D. J. Influence of lipid phase composition of excipient emulsions on curcumin solubility, stability, and bioaccessibility. Food Biophys. 2016, 11, 213-225. DOI: $10.1007 / \mathrm{s} 11483-016-9432-9$.

(59) Rakotoarisoa, M.; Angelov, B.; Garamus, V.M.; Angelova, A. Curcumin- and fish oilloaded spongosome and cubosome nanoparticles with neuroprotective potential against H2O2-induced oxidative stress in differentiated human SH-SY5Y cells. ACS Omega 2019, 4, 3061-3073. DOI: 10.1021/acsomega.8b03101.

(60) Rakotoarisoa, M.; Angelova, A. Amphiphilic nanocarrier systems for curcumin delivery in neurodegenerative disorders. Medicines 2018, 5, 126. DOI: 10.3390/medicines5040126. 
(61) Chatzidaki, M. D.; Mitsou, E.; Yaghmur, A.; Xenakis, A.; Papadimitriou, V. Formulation and characterization of food-grade microemulsions as carriers of natural phenolic antioxidants. Colloids Surf. A 2015, 483, 130-136. DOI: 10.1016/j.colsurfa.2015.03.060

(62) Jiang, T.; Liao, W.; Charcosset, C. Recent advances in encapsulation of curcumin in nanoemulsions: A review of encapsulation technologies, bioaccessibility and applications. Food Res Int. 2020, 132, 109035. DOI: 10.1016/j.foodres.2020.109035.

(63) Van Hoogevest, P.; Wendel, A. The use of natural and synthetic phospholipids as pharmaceutical excipients. Eur. J. Lipid Sci. Tech. 2014, 116, 1088-1107. DOI: 10.1002/ejlt.201400219.

(64) Richter, C.K.; Skulas-Ray, A.C.; Kris-Etherton, P.M. "Chapter 3: Recommended intake of fish and fish oils worldwide," in Fish and Fish Oil in Health and Disease Prevention. Eds. S. K. Raatz and D. M. Bibus (San Diego, CA: Academic Press), 2016, 27-48. DOI: 10.1016/B978-0-12-802844-5.00003-8.

(65) Cholewski, M.; Tomczykowa, M.; Tomczyk, M. A Comprehensive Review of Chemistry, Sources and Bioavailability of Omega-3 Fatty Acids. Nutrients. 2018, 10, 1662. DOI: 10.3390/nu10111662.

(66) Wang, W.; Zhu, J.; Lyu, F.; Panigrahy, D.; Ferrara, K.W.; Hammock, B.; Zhang, G. w-3 Polyunsaturated fatty acids-derived lipid metabolites on angiogenesis, inflammation and cancer. Prostaglandins Other Lipid Mediators 2014, 113-115, 13-20. DOI: 10.1016/j.prostaglandins.2014.07.002.

(67) Khaddaj-Mallat, R.; Morin, C.; Rousseau, E. Novel n-3 PUFA monoacylglycerides of pharmacological and medicinal interest: Anti-inflammatory and anti-proliferative effects. Eur. J. Pharmacol. 2016, 792, 70-77.3. DOI: 10.1016/j.ejphar.2016.10.038.

(68) Morin, C.; Rodriguez, E.; Blier, P.U.; Fortin, S. Potential application of eicosapentaenoic acid monoacylglyceride in the management of colorectal cancer. Mar. Drugs 2017, 15, 283. DOI: $10.3390 / \mathrm{md} 15090283$.

(69) Burhani, M.D.; Rasenick, M.M. Fish oil and depression: The skinny on fats. J. Integr. Neurosci. 2017, 16(s1):S115-S124. DOI: 10.3233/JIN-170072.

(70) Morin, C.; Rousseau, E.; Blier, P.U.; Fortin, S. Effect of docosahexaenoic acid monoacylglyceride on systemic hypertension and cardiovascular dysfunction, Am. J. Physiol.: Heart Circ. Physiol. 2015, 309, H93-H102. DOI: 10.1152/ajpheart.00823.2014.

(71) Morin, C.; Rousseau, E.; Fortin, S. Anti-proliferative effects of a new docosapentaenoic acid monoacylglyceride in colorectal carcinoma cells. Prostaglandins, Leukotrienes Essent. Fatty Acids 2013, 89, 203-213. DOI: 10.1016/j.plefa.2013.07.004.

(72) Leslie, M.A.; Cohen, D.; Liddle, D.M.; Robinson, L.E.; Ma, D.W. A review of the effect of omega-3 polyunsaturated fatty acids on blood triacylglycerol levels in normolipidemic and borderline hyperlipidemic individuals. Lipids Health Dis. 2015, 14, 53. DOI: 10.1186/s12944-015-0049-7. 
(73) Sakamoto, A.; Saotome, M.; Iguchi, K.; Maekawa, Y. Marine-derived omega-3 polyunsaturated fatty acids and heart failure: Current understanding for basic to clinical relevance. Int. J. Mol. Sci. 2019, 20, 4025. DOI: 10.3390/ijms20164025.

(74) Ma, Q.L.; Teter, B.; Ubeda, O.J.; Morihara, T.; Dhoot, D.; Nyby, M.D.; Tuck, M.L.; Frautschy, S.A.; Cole, G.M. Omega-3 fatty acid docosahexaenoic acid increases SorLA/LR11, a sorting protein with reduced expression in sporadic Alzheimer's disease (AD): relevance to AD prevention. $J$ Neurosci, 2007, 27, 14299-14307. DOI: 10.1523/JNEUROSCI.3593-07.2007.

(75) Ulven, S.M.; Holven, K.B. Comparison of bioavailability of krill oil versus fish oil and health effect. Vasc. Health Risk Manag. 2015, 11, 511-524. DOI: 0.2147/VHRM.S85165.

(76) Walker, R.; Decker, E.A.; McClements, D.J. Development of food-grade nanoemulsions and emulsions for delivery of omega-3 fatty acids: opportunities and obstacles in the food industry. Food Funct. 2015, 6, 42-55. DOI: 10.1039/c4fo00723a

(77) Wang, J.; Luo, T.; Li. S.; Zhao, J. The powerful applications of polyunsaturated fatty acids in improving the therapeutic efficacy of anticancer drugs. Expert Opinion on Drug Delivery 2012, 9, 1-7. DOI: 10.1517/17425247.2011.618183.

(78) Berquin, I.M.; Edwards, I.J.; Chen, Y.Q. Multi-targeted therapy of cancer by omega-3 fatty acids. Cancer Lett. 2008, 269, 363-377. DOI: 10.1016/j.canlet.2008.03.044.

(79) Pan, Y.; Khalil, H.; Nicolazzo, J. The impact of docosahexaenoic acid on Alzheimer's disease: Is there a role of the blood-brain barrier? Curr. Clin. Pharmacol. 2015, 10, 222-241. DOI: 10.2174/157488471003150820151532.

(80) Bousquet, M.; Saint-Pierre, M.; Julien, C.; Salem, N.; Cicchetti, F.; Calon, F. Beneficial effects of dietary omega-3 polyunsaturated fatty acid on toxin-induced neuronal degeneration in an animal model of Parkinson's disease. FASEB J. 2008, 22, 1213-1225. DOI: doi: 10.1096/fj.07-9677com.

(81) Shehzad, Q.; Rehman, A.; Jafari, S.M.; Zuo, M.; Khan, M.A.; Ali, A.; Khan, S.; Karim, A.; Usman, M., Hussain, A. Xia, W. Improving the oxidative stability of fish oil nanoemulsions by co-encapsulation with curcumin and resveratrol. Colloids Surf B Biointerfaces. 2021, 199, 111481. DOI: 10.1016/j.colsurfb.2020.111481.

(82) Gulotta, A.; Saberi, A.H.; Nicoli, M.C.; McClements, D.J. Nanoemulsion-based delivery systems for polyunsaturated (omega-3) oils: formation using a spontaneous emulsification method. Journal of agricultural and food chemistry 2014, 62, 1720-1725. DOI: $10.1021 / \mathrm{jf} 4054808$.

(83) Dey, K.T.; Ghosh, S.; Ghosh, M.; Koley, H.; Dhar, P. Comparative study of gastrointestinal absorption of EPA \& DHA rich fish oil from nano and conventional emulsion formulation in rats. Food research international 2012, 49, 72-79. DOI: 10.1016/j.foodres.2012.07.056.

(84) Venugopalan, V.K.; Gopakumar, L.R.; Kumaran, A.K.; Chatterjee, N.S.; Soman, V.; Peeralil, S.; Mathew, S.; McClements, D.J.; Nagarajarao RC. Encapsulation and protection 
of omega-3-rich fish oils using food-grade delivery systems. Foods. 2021, 10, 1566. DOI: $10.3390 /$ foods 10071566 .

(85) Den Ruijter, H.M.; Berecki, G.; Opthof, T.; Verkerk, A.O.; Zock, P.L.; Coronel, R. Proand antiarrhythmic properties of a diet rich in fish oil. Cardiovasc Res. 2007, 73, 316-325. DOI: 10.1016/j.cardiores.2006.06.014.

(86) Jafari, S.M.; Assadpoor, E.; Bhandari, B.; He, Y. Nano-particle encapsulation of fish oil by spray drying. Food Research International 2008, 41, 172-183. DOI: 10.1016/j.foodres.2007.11.002.

(87) Kalmijn, S.; van Boxtel, M.P.; Ocke, M.; Verschuren, W.M.; Kromhout, D.; Launer, L.J. Dietary intake of fatty acids and fish in relation to cognitive performance at middle age. Neurology 2004, 62, 275-280. DOI: 10.1212/01.wnl.0000103860.75218.a5.

(88) Barbosa, D.S.; Cecchini, R.; El Kadri, M.Z.; Rodríguez, M.A.; Burini, R.C.; Dichi, I. Decreased oxidative stress in patients with ulcerative colitis supplemented with fish oil omega. Nutrition. 2003, 19, 837-42. DOI: 10.1016/s0899-9007(03)00162-x.

(89) Zheng, M.; Wang, Z.; Liu, F.; Mi, Q.; Wu, J. Study on the microstructure and rheological property of fish oil lyotropic liquid crystal. Colloids and Surfaces A: Physicochemical and Engineering Aspects 2011, 385, 47-54. DOI: 10.1016/j.colsurfa.2011.05.040.

(90) Nilsson, C.; Edwards, K.; Eriksson, J.; Larsen, S.W.; Østergaard, J.; Larsen, C.; Urtti, A.; Yaghmur, A. Characterization of oil-free and oil-loaded liquid-crystalline particles stabilized by negatively charged stabilizer citrem. Langmuir 2012, 28, 11755-11766. DOI: 10.1021/la3021244. Epub 2012 Aug 3.

(91) Angelova, A.; Drechsler, M.; Garamus, V. M.; Angelov, B. Liquid crystalline nanostructures as pegylated reservoirs of omega-3 polyunsaturated fatty acids: structural insights toward delivery formulations against neurodegenerative disorders. ACS Omega 2018, 3, 3235-3247. DOI: 10.1021/acsomega.7b01935

(92) Shao, X.; Bor, G.; Al-Hosayni, S.; Salentinig, S.; Yaghmur, A. Structural characterization of self-assemblies of new omega-3 lipids: docosahexaenoic acid and docosapentaenoic acid monoglycerides. Phys Chem Chem Phys. 2018, 20, 23928-23941. DOI: $10.1039 / \mathrm{c} 8 \mathrm{cp} 04256 \mathrm{j}$.

(93) Yaghmur, A.; Al-Hosayni, S.; Amenitsch, H.; Salentinig, S. Structural investigation of bulk and dispersed inverse lyotropic hexagonal liquid crystalline phases of eicosapentaenoic acid monoglyceride. Langmuir 2017, 33, 14045-14057. DOI: 10.1021/acs.langmuir.7b03078.

(94) Yaghmur, A., de Campo, L., Sagalowicz, L., Leser, M.E., Glatter, O. Emulsified microemulsions and oil-containing liquid crystalline phases. Langmuir 2005, 21, 569-577. DOI: $10.1021 / \mathrm{la} 0482711$.

(95) Yaghmur, A., Ghazal, A., Ghazal, R., Dimaki, M., Svendsen, W.E. A hydrodynamic flow focusing microfluidic device for the continuous production of hexosomes based on docosahexaenoic acid monoglyceride. Phys. Chem. Chem. Phys. 2019, 21, 13005-13013. DOI: $10.1039 / \mathrm{c} 9 \mathrm{cp} 02393 \mathrm{c}$. 
(96) Angelova, A.; Angelov, B.; Garamus, V. M.; Couvreur, P.; Lesieur, S. Small-angle X-ray scattering investigations of biomolecular confinement, loading, and release from liquidcrystalline nanochannel assemblies. J. Phys. Chem. Lett. 2012, 3, 445-457. DOI: 10.1021/jz2014727. Epub 2012 Jan 24.

(97) Yaghmur, A.; Lotfi, S.; Ariabod, S.A., Bor, G.; Gontsarik, M.; Salentinig, S. Internal Lamellar and Inverse Hexagonal Liquid Crystalline Phases During the Digestion of Krill and Astaxanthin Oil-in-Water Emulsions. Front Bioeng Biotechnol. 2019, 7, 384. DOI: 10.3389/fbioe.2019.00384.

(98) Fong, C.; Zhai, J.; Drummond, C.J.; Tran, N. Micellar Fd3m cubosomes from monoolein long chain unsaturated fatty acid mixtures: Stability on temperature and $\mathrm{pH}$ response. $J$ Colloid Interface Sci. 2020, 566, 98-106. DOI: 10.1016/j.jcis.2020.01.041.

(99) Thormar, H.; Isaacs, C.E.; Brown, H.R.; Barshatzky, M.R., Pessolano, T. Inactivation of enveloped viruses and killing of cells by fatty acids and monoglycerides. Antimicrobial Agents and Chemotherapy. 1987, 31, 27-31. DOI: 10.1128/AAC.31.1.27.

(100) Knapp, H.R.; Melly, M.A.; Knapp, H.R. Bactericidal effects of polyunsaturated fatty acids. The Journal of Infectious Diseases. 1986, 154, 84-94. DOI: 10.1093/infdis/154.1.84.

(101) Deng, Y.; Angelova A. Coronavirus-induced host cubic membranes and lipid-related antiviral therapies: A focus on bioactive plasmalogens. Front. Cell Dev. Biol. 2021, 9, 630242. DOI:

(102) Schoenmaker, L.; Witzigmann, D.; Kulkarni, J.A.; Verbeke, R.; Kersten, G.; Jiskoot, W.; Crommelin, D.J.A. mRNA-lipid nanoparticle COVID-19 vaccines: Structure and stability. Int. J. Pharm. 2021, 601, 120586. DOI: 10.1016/j.ijpharm.2021.120586.

(103) Eygeris, Y.; Patel, S.; Jozic, A.; Sahay. G. Deconvoluting lipid nanoparticle structure for messenger RNA delivery. Nano Letters 2020, 20, 4543-4549. DOI:

(104) Kim, J.; Eygeris, Y.; Gupta, M.; Sahay, G. Self-assembled mRNA vaccines. Adv. Drug Delivery Rev. 2021, 170 , 83-112. DOI: 10.1021/acs.nanolett.0c01386.

(105) Pilkington, E.H.; Suys, E.J.A.; Trevaskis, N.L.; Wheatley, A.K.; Zukancic, D.; Algarni, A.; Al-Wassiti, H.; Davis, T.P.; Pouton, C.W.; Kent, S.J.; Truong, N.P. From influenza to COVID-19: Lipid nanoparticle mRNA vaccines at the frontiers of infectious diseases. Acta Biomaterialia 2021, 131, 16-40. DOI:10.1016/j.actbio.2021.06.023.

(106) David, G.; Pérez, J. Combined sampler robot and high-performance liquid chromatography: a fully automated system for biological small-angle X-ray scattering experiments at the synchrotron SOLEIL SWING beamline. J. Applied Crystallography, 2009, 42, 892-900. DOI: 10.1107/S0021889809029288. 